\title{
Research on the Influence of Nanocarbon/Copolymer SBS/Rubber Powder Composite Modification on the Properties of Asphalt and Mixtures
}

\author{
Wenhui Zhao, ${ }^{1}$ Xiangbing Xie, ${ }^{1}$ Guanghui Li $\left(\mathbb{D},{ }^{1}\right.$ Jiuguang Geng, ${ }^{2}$ Meng Bao, ${ }^{1}$ \\ and Mingwei Wang ${ }^{1}$ \\ ${ }^{1}$ School of Civil Engineering and Architecture, Zhengzhou University of Aeronautics, Zhengzhou, Henan 450046, China \\ ${ }^{2}$ School of Materials Science and Engineering, Chang'an University, Xi'an, Shanxi 710061, China \\ Correspondence should be addressed to Guanghui Li; lgh@zua.edu.cn
}

Received 21 September 2020; Revised 18 November 2020; Accepted 2 December 2020; Published 23 December 2020

Academic Editor: Jun Liu

Copyright (C) 2020 Wenhui Zhao et al. This is an open access article distributed under the Creative Commons Attribution License, which permits unrestricted use, distribution, and reproduction in any medium, provided the original work is properly cited.

\begin{abstract}
To expand the application range of modified asphalt and mixtures and effectively reduce the aggregation of nanomaterials in asphalt, nanocarbon/styrene butadiene styrene (SBS)/rubber powder composite-modified asphalt is proposed. This paper presents a laboratory study on the performance of nanocarbon/copolymer SBS/rubber powder composite-modified asphalt, and nanocarbon particles modified by titanate coupling agents as modifiers are selected. The nanocarbon/copolymer SBS/rubber powder composite-modified asphalt was prepared by a high-speed shearing method. The physical properties and rheological performance were assessed using ductility tests, softening point tests, penetration tests, dynamic shear rheometer (DSR) tests, and bending beam rheometer (BBR) tests. Furthermore, the mixture properties, including the high-temperature stability, lowtemperature cracking resistance, moisture stability, and freeze-thaw splitting, were evaluated in the laboratory. The micromorphology of the base asphalt and composite-modified asphalt was examined by scanning electron microscopy (SEM), and the reactions between the modifiers and AH-70 base asphalt were studied by Fourier transform infrared spectroscopy (FTIR). The results reveal that the surface-modified nanocarbon and rubber powder additives substantially increased the softening point and penetration index of the base asphalt, with little obvious influence on the low-temperature performance. In addition, when nanocarbon/copolymer SBS/rubber powder composite-modified asphalt was used, the high-temperature stability and lowtemperature cracking resistance of the nanocarbon/copolymer SBS/rubber powder composite-modified asphalt mixture were approximately 1.3 times those of the nanocarbon/rubber powder asphalt mixture. In terms of the micromorphology and reaction, the addition of the nanocarbon can increase the compatibility between the base asphalt and rubber powder, and then the addition of copolymer SBS can improve the structure of nanocarbon (after surface modification)/rubber powder-modified asphalt to form a stable network. Moreover, the physical reaction plays the dominant role in the modification process for the rubber powder and base asphalt, and chemical reactions occur in the modification process for the surface-modified nanocarbon and base asphalt.
\end{abstract}

\section{Introduction}

In road engineering, asphalt pavement is widely used due to its smooth surface, comfortable driving, low vibration, low noise, and short construction period. With the increase in traffic loads and the complexity of the road service environment, asphalt pavement is prone to rutting, cracking, and other defects. However, traditional asphalt pavements can no longer fully meet the needs of modern and future transportation development. There is an urgent need to develop high-performance asphalt materials.

SBS-modified asphalt has excellent properties. Due to the poor compatibility of SBS and asphalt, the development and application of SBS-modified asphalt are severely restricted $[1,2]$. Su and authors suggested that nanomaterials could increase the dispersion of polymers in base asphalt and improve the compatibility between the polymer and base asphalt [3]. From the perspective of environmental 
protection and modification effects, rubber powder-modified asphalt is a new type of high-quality composite material, but rubber powder-modified asphalt has a large viscosity and poor thermal storage stability [4]. The effect of nano-organic montmorillonite (NOMMT) on the performance of rubbermodified asphalt was studied by Tian and authors. The results show that the addition of NOMMT improves the thermal stability and antiaging performance of rubber asphalt. Through micromechanism analysis, it is pointed out that NOMMT has good compatibility with rubber powder [5]. With the development of nanotechnology, an increasing number of scholars have begun to study the application of nanomaterials in asphalt modification [6]. Carbon nanomaterials have a large specific surface area, which can effectively improve the performance of asphalt binders [7, 8]. Xiao and authors utilized this material to modify base asphalt and found that nanocarbon can substantially improve the viscoelastic properties and antiaging properties of asphalt binder [9-11]. From the perspective of the modification effect, a single modifier lacks synergy, and it is difficult to fully utilize its excellent properties.

To further improve the composite modification effect of modifiers on asphalt and mixtures, the combined use of multiple modifiers has become a new approach to improve the comprehensive performance of asphalt and asphalt mixtures. Sun and authors reported that a compositemodified technique using nano- $\mathrm{SiO}_{2}$, styrene butadiene rubber (SBR) and polyethylene (PE) could comprehensively improve the high-temperature performance, low-temperature performance, and aging resistance of asphalt binders [12]. He and authors conducted research on SBS/rubber powder-modified asphalt, and the results showed that the flexibility and structure of the SBS/rubber powder composite-modified asphalt after UV aging were not greatly affected. Dynamic shear rheometer (DSR) and bending beam rheometer (BBR) tests showed that the compositemodified asphalt still had excellent temperature sensitivity and low-temperature crack resistance after aging, and the modification of asphalt by SBS and rubber powder was mainly physical modification [13]. Mo and authors performed DSR tests, rutting tests and three-point bending tests and demonstrated that SBS/rubber powder compositemodified asphalt had good performance in both high- and low-temperature environments, and the addition of composite-modified materials improved the rutting resistance and low-temperature crack resistance of asphalt mixtures [14]. Moreover, many researchers have illustrated that compared to a single modifier, SBR/SBS/rubber powder composite-modified asphalt has better viscoelastic properties, and the composite of the SBR/SBS/rubber powder modification method substantially improves the high-temperature rutting resistance, low-temperature crack resistance, moisture stability, and fatigue resistance performance of asphalt mixtures [15-17].

In the above studies, many researchers have suggested that copolymer SBS, rubber powder, and nanomaterials can improve the performance of asphalt and mixtures, but the modification ability of a single modifier is limited. From the perspective of environmental protection and modification effects, the use of multiple modifiers to modify asphalt is one of the topics worthy of in-depth study. Therefore, based on the comprehensive consideration of environmental protection and modification effects, combined with the research results of our research group [18], this research chose AH-70 base asphalt as the modified object and adopted high-speed shear technology to prepare $2 \%$ nanocarbon-modified asphalt, $18 \%$ rubber powder-modified asphalt, $2 \%$ nanocarbon/18\% rubber powder-modified asphalt, and $2 \%$ nanocarbon $/ 1.0 \%$ copolymer SBS/18\% rubber powdermodified asphalt, while the comprehensive performance of the modified asphalt and mixture was evaluated through laboratory tests.

\section{Materials}

2.1. Raw Materials. The base asphalt AH-70 in this paper was provided by Maoming Asphalt Co. Ltd. (Guangdong Province, China), and its main properties are reported in Table 1 according to the standard test methods in China test specification JTG E 20 [19]. The properties of carbon nanoparticles, copolymer SBS, and rubber powder are shown in Tables 2-4, respectively.

\subsection{Surface Modification Process of Carbon Nanoparticles.} Titanate coupling agents (TMC931) are a type of surface modification in the field of composite materials, and the modification of nanocarbon particles with titanate coupling agents can improve the dispersion effect of nanocarbon powder in asphalt. First, the titanate coupling agent diluent solution was prepared with the titanate coupling agent and absolute ethanol with a weight ratio of $7: 3$, and the diluted titanate coupling agent solution was mixed with carbon nanoparticles with a weight ratio of $1: 10$. A blender was used to stir the mixture for 10 minutes, and the mixture was placed in an oven at a set temperature of $130^{\circ} \mathrm{C}$ for 15 minutes. Then, the mixture was stirred a second time. After stirring, it was ground with a glass rod to form a powder. Finally, surface-modified nanocarbon particles were obtained $[20,21]$.

2.3. Preparation of the Modified Asphalt. In this paper, we choose $70^{\#}$ base asphalt as the modified object. To prepare the modified asphalt, the base asphalt was heated in an iron container until it became fluid. First, the carbon nanoparticles and the base asphalt were sheared together in a high shear emulsifier for $20 \mathrm{~min}$ with a rotation speed of $1500 \mathrm{r} / \mathrm{min}$ at $160^{\circ} \mathrm{C}$. Then, the mixture was stirred with a shear rotation speed of $4000 \mathrm{r} / \mathrm{min}$ for $30 \mathrm{~min}$ at $160^{\circ} \mathrm{C}$ by a high shear emulsifier to obtain the nanocarbon-modified asphalt. The copolymer SBS was added into the nanocarbon-modified asphalt at $180^{\circ} \mathrm{C}$ for $20 \mathrm{~min}$ with a shear rotation speed of $1500 \mathrm{r} / \mathrm{min}$ by stirring, and then the mixture was stirred with a shear rotation speed of $5000 \mathrm{r} / \mathrm{min}$ for $40 \mathrm{~min}$ at $180^{\circ} \mathrm{C}$ by a high shear emulsifier. Third, the rubber powder and nanocarbon/SBS-modified asphalt were sheared together for $20 \mathrm{~min}$ with a rotation speed of $1500 \mathrm{r} / \mathrm{min}$ at $180^{\circ} \mathrm{C}$ by stirring. After that, the mixture was stirred with a shear 
TABle 1: Properties of the base asphalt.

\begin{tabular}{lccr}
\hline Items & Technical indexes & Results & Standard \\
\hline Penetration $\left(25^{\circ} \mathrm{C}, 100 \mathrm{~g}, 5 \mathrm{~s}\right) / 0.1 \mathrm{~mm}$ & $60 \sim 80$ & 67 & JTG E20-T 0604 \\
Penetration index $(\mathrm{PI})$ & $-1.5-+1.0$ & -1.31 & $\mathrm{JTG}$ E20-T 0604 \\
Softening point $\left({ }^{\circ} \mathrm{C}\right)$ & $\geq 46$ & 48.0 & $\mathrm{JTG}$ E20-T 0606 \\
$60^{\circ} \mathrm{C}$ dynamic viscosity $(\mathrm{Pa} . \mathrm{s})$ & $\geq 180$ & 208 & $\mathrm{JTG}$ E20-T 0620 \\
$10^{\circ} \mathrm{C}$ ductility $(\mathrm{cm})$ & $\geq 15$ & 31.8 & $\mathrm{JTG}$ E20-T 0605 \\
$15^{\circ} \mathrm{C}$ ductility $(\mathrm{cm})$ & $\geq 100$ & $>100$ & $\mathrm{JTG} \mathrm{E20-T} \mathrm{0605}$ \\
\hline
\end{tabular}

TABle 2: Properties of carbon nanoparticles.

\begin{tabular}{lccc}
\hline Nanomaterial & Particle size $(\mathrm{nm})$ & Specific surface area $\left(\mathrm{m}^{2} \cdot \mathrm{g}^{-1}\right)$ & Apparent density $\left(\mathrm{g} / \mathrm{cm}^{-3}\right)$ \\
\hline Nanocarbon & 20 & 318.26 & 0.86 \\
\hline
\end{tabular}

TABle 3: Physical properties of the SBS copolymer.

\begin{tabular}{lcccc}
\hline Structures & $S / B$ (mass ratio) & Tensile strength $(\mathrm{MPa})$ & $300 \%$ constant stress $(\mathrm{MPa})$ & Tensile elongation $(\%)$ \\
\hline Linear & $30 / 70$ & 15.0 & 2.0 & 700 \\
\hline
\end{tabular}

TABle 4: Properties of the rubber powder.

\begin{tabular}{lccc}
\hline Particle size $(\mathrm{mm})$ & Color & Rubber hydrocarbon content $(\%)$ & Bulk density $\left(\mathrm{kg} / \mathrm{m}^{-3}\right)$ \\
\hline 0.45 & Black & 53 & 337 \\
\hline
\end{tabular}

rotation speed of $5000 \mathrm{r} / \mathrm{min}$ for $40 \mathrm{~min}$ at $180^{\circ} \mathrm{C}$ by a high shear emulsifier. Finally, the composite-modified asphalt was put into an oven for $30 \mathrm{~min}$ at $160^{\circ} \mathrm{C}$ to mix the nanocarbon/ copolymer SBS/rubber powder-modified asphalt well [22, 23]. In this paper, the abbreviations of the mixtures are shown in Table 5.

2.4. Asphalt Mixture. The aggregates and mineral filler were processed from limestone. The aggregate gradation of AC-13 was used, and the aggregate gradation is shown in Figure 1. The optimal asphalt content for asphalt mixtures was determined by the Marshall method. As a result, the optimal asphalt aggregate ratios of the base asphalt mixture, nanocarbon-modified asphalt mixture, rubber-modified asphalt mixture, nanocarbon/rubber powder-modified asphalt mixture, and nanocarbon/copolymer SBS/rubber powdermodified asphalt mixture were determined to be $4.8 \%, 4.9 \%$, $5.1 \%, 5.1 \%$, and $5.2 \%$, respectively.

\section{Experiment Methods}

3.1. Segregation Test. According to the standard test methods in China test specification JTG E20 [19], the compatibility of each modifier with the base asphalt can be evaluated by a segregation test. First, each modified asphalt is poured into an upright aluminum tube after heating. The mass of the modified asphalt is approximately $50 \mathrm{~g}$, and the aluminum tubes containing modified asphalt binder are shown in Figure 2. Second, the open end of the sample containing the aluminum tube is sealed and placed vertically in an oven at $163^{\circ} \mathrm{C} \pm 5^{\circ} \mathrm{C}$ and allowed to stand for 48 hours. The third step is to remove the aluminum tube from the oven and put it in the refrigerator for 4 hours. Finally, the aluminum tube containing modified asphalt is removed, the aluminum tube is cut into 3 sections with scissors, and the asphalt of the upper and lower parts of the aluminum tube is heated and poured into the softening point mold. The softening point of the upper and lower asphalt is determined, and the difference is calculated. The smaller the difference is, the better the compatibility of the modifier and the asphalt.

3.2. Conventional Physical Properties Test. The conventional physical properties of the base asphalt and modified asphalt, including the ductility $\left(5 \mathrm{~cm} / \mathrm{min}, 5^{\circ} \mathrm{C}\right)$, softening point, and penetration (at $15^{\circ} \mathrm{C}, 25^{\circ} \mathrm{C}, 30^{\circ} \mathrm{C}, 100 \mathrm{~g}$, and $0.1 \mathrm{~mm}$ ), were tested according to the standard test methods in China test specification JTG E20 [19]. To further study the role of each modified material in the asphalt based on test results, the penetration index (PI) is calculated according to the following equation:

$$
\mathrm{PI}=\frac{20-500 A_{\mathrm{lgPen}}}{1+50 A_{\mathrm{lgPen}}},
$$

where $\mathrm{A}_{\operatorname{lgPen}}$ is the penetration temperature index.

3.3. Dynamic Shear Rheometer (DSR) Test. The DSR test can be used to measure both the viscous and elastic behaviors of asphalt binder. A dynamic shear rheometer DSR-MCR302 \& MCR102 from Anton Paar Company, Austria, was used to characterize the rheological properties of nanomodified asphalt samples from the complex shear modulus, phase angle, and loss factor through strain sweep, temperature 
TABLE 5: Abbreviation of the mixtures.

\begin{tabular}{lc}
\hline Mixtures & Abbreviation \\
\hline Nanocarbon- modified asphalt (before surface modification) & NcPb MA \\
Nanocarbon- modified asphalt (after surface modification) & NcPa MA \\
Rubber powder-modified asphalt & RP MA \\
Nanocarbon (after surface modification)/rubber powder-modified asphalt & NcPa-RP MA \\
Nanocarbon (after surface modification)/SBS/rubber powder-modified asphalt & NcPa-SBS-RP MA \\
\hline
\end{tabular}

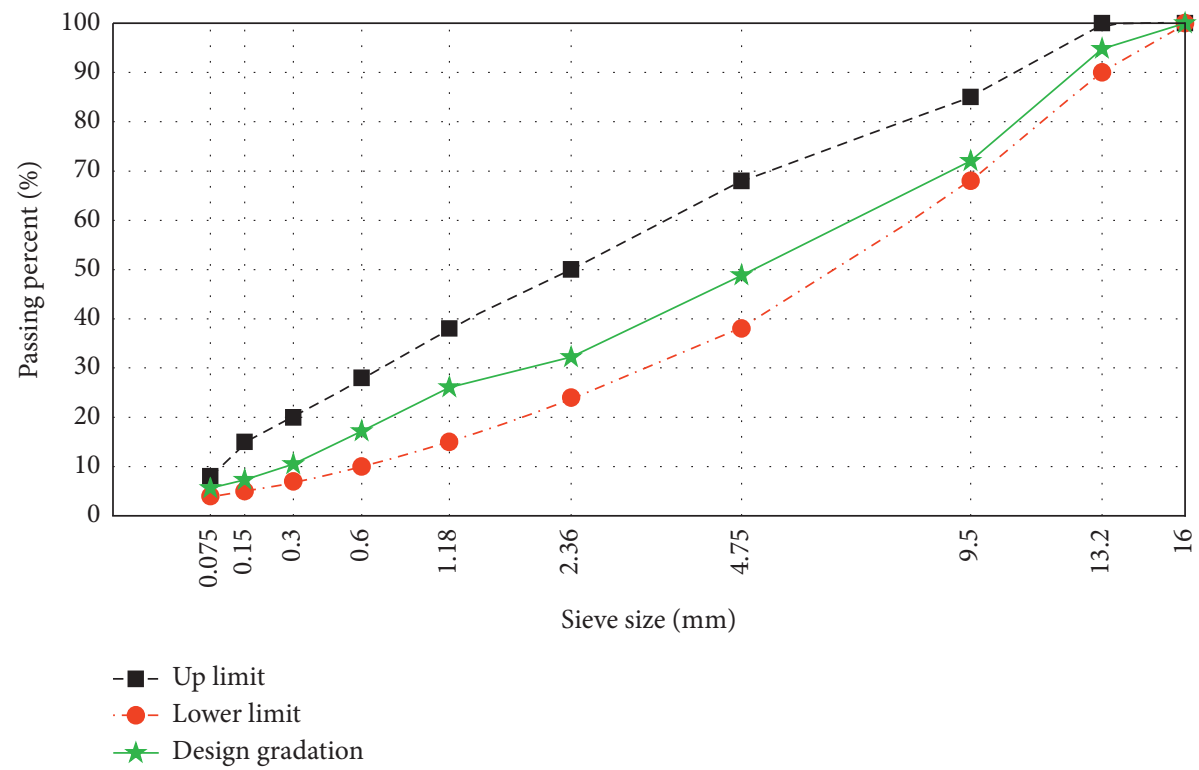

Figure 1: Aggregate gradation.

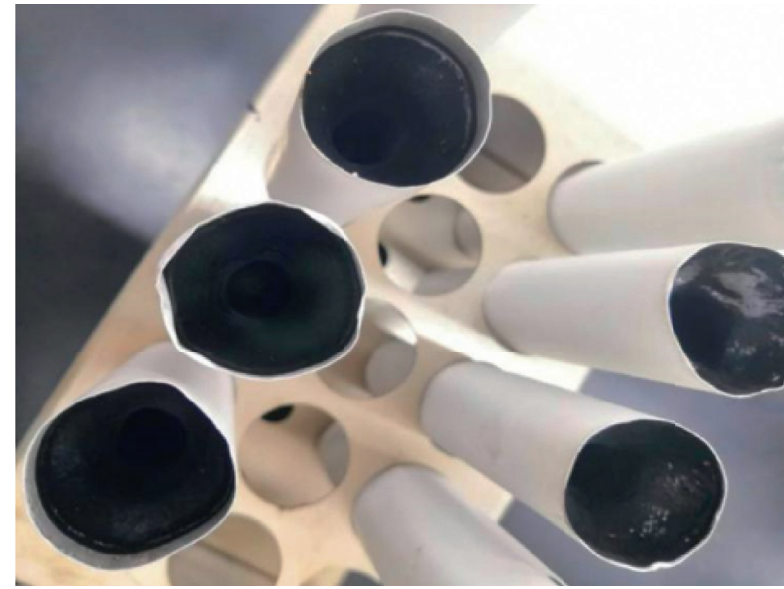

FIgURE 2: Aluminum pipe with modified asphalt.

sweep, and frequency sweep tests according to ASTM D 7175 [24]. The test parameter settings are shown in Table 6.

3.4. Bending Beam Rheometer (BBR) Test. According to AASHTO [25], a bending beam rheometer (BBR) test was carried out to test the low-temperature creep of base asphalt and modified asphalt binder at $-18^{\circ} \mathrm{C}$. The specimens were removed from the mold after cooling in a freezer for $10 \mathrm{~min}$. Then, the beam was kept in the testing bath for $60 \mathrm{~min}$ before testing. After parameter setting, a $980 \mathrm{mN}$ load was applied to the specimen for $240 \mathrm{~s}$. The creep stiffness $(S)$ and creep rate $(m)$ were used to characterize the low-temperature performance of the asphalt binder. The creep stiffness $(S)$ represents the ability of asphalt to resist deformation, and the value of the creep rate $(m)$ reflects the sensitivity of the asphalt stiffness over time and the stress relaxation ability [26].

3.5. Scanning Electron Microscopy (SEM) Test. Scanning electron microscopy (SEM) was employed to observe the microstructure changes of the modified asphalt, as well as the physical dispersion of the nanoparticles, rubber powder, and copolymer SBS. A certain amount of asphalt was taken as the test sample, and metal films were deposited on the surface of the samples in a vacuum state by using an ion plating apparatus for $100 \mathrm{~s}$. The morphology of the base and modified asphalt were observed using a JSM-7001F scanning electron microscope from Japan Co. Ltd.

3.6. Fourier Transform Infrared Spectroscopy (FTIR) Test. Fourier transform infrared spectroscopy (FTIR) is a technique that can qualitatively and quantitatively analyze samples. Nicolet Nexus Fourier transform infrared spectroscopy (FTIR) from Nicolet Company was used to acquire the FTIR spectra of modified asphalt binder samples. An 
TABLE 6: Settings of the parameters.

\begin{tabular}{lccr}
\hline Test type & Temperature $\left({ }^{\circ} \mathrm{C}\right)$ & Load pattern & Loading frequency $(\mathrm{Hz})$ \\
\hline Strain sweep & 60 & Strain control $(0.1 \% \sim 10 \%)$ & 1.59 \\
Temperature sweep & $40 \sim 80$ & Strain control $(2 \%)$ & 1.59 \\
Frequency sweep & 60 & Strain control $(2 \%)$ & $0.1 \% \sim 10 \%$ \\
\hline
\end{tabular}

asphalt binder and carbon disulfide $\left(\mathrm{C}_{2} \mathrm{~S}\right)$ solution were made at a certain concentration and poured onto a small potassium bromide $(\mathrm{KBr})$ crystal sample plate. The test started after the complete volatilization of $\mathrm{C}_{2} \mathrm{~S}$. The width range of the wavenumber was from 400 to $4000 \mathrm{~cm}^{-1}$ at a resolution of $4 \mathrm{~cm}^{-1}$.

3.7. Rutting Test. The high-temperature performance of the asphalt mixture was reflected by dynamic stability in accordance with JTG E20 [19]. The specimens $(300 \mathrm{~mm} \times 300 \mathrm{~mm} \times 50 \mathrm{~mm})$ were rolled and formed by a wheel rolling machine, and three parallel samples are required for each asphalt mixtures. The test temperature was set to $60^{\circ} \mathrm{C}$, and the pressure of the wheel load was $0.7 \mathrm{MPa}$. The dynamic stability (DS) was calculated to characterize the antirutting ability of asphalt mixtures at high temperature and is defined by the following equation:

$$
\mathrm{DS}=\frac{\left(t_{2}-t_{1}\right) \times N}{d_{2}-d_{1}} \times C_{1} \times C_{2},
$$

where $d_{1}$ is the deformation at time $t_{1}(45 \mathrm{~min}), d_{2}$ is the deformation at time $t_{2}(60 \mathrm{~min}), N$ refers to the rolling speed (taken as 42 times/min), $C_{1}$ is the testing machine coefficient, and $C_{2}$ is the specimen coefficient.

3.8. Low-Temperature Trabecular Bending Test. The temperature stress test is one of the important methods used to evaluate the low-temperature crack resistance of asphalt mixtures. In this paper, according to JTG E20 [19], the flexural tensile modulus, flexural strength, and flexural stiffness modulus of trabecular beam specimens at low temperature were used to comprehensively evaluate the lowtemperature crack resistance of asphalt mixtures. The specimens $(250 \mathrm{~mm} \times 30 \mathrm{~mm} \times 35 \mathrm{~mm})$ for the bending beam test were sawed from wheel tracking test specimens, and three parallel samples are required for each asphalt mixtures. The specimens were loaded at a ratio of $50 \mathrm{~mm} /$ $\min$, and the temperature was set to $-10^{\circ} \mathrm{C}$. The flexural tensile strength $R_{B}$, flexural tensile strain $\varepsilon_{N}$, and flexural stiffness modulus $S_{B}$ when the specimen fails are calculated by the following equations:

$$
\begin{aligned}
R_{B} & =\frac{3 \times L \times P_{B}}{2 \times b \times h^{2}}, \\
\varepsilon_{B} & =\frac{6 \times h \times d}{L^{2}}, \\
S_{B} & =\frac{R_{B}}{\varepsilon_{B}},
\end{aligned}
$$

where $P_{B}$ is the maximum load, $L$ is the span of the specimen, $h$ is the height of the specimen, and $b$ is the width of the specimen.

3.9. Marshall Test. The antistripping ability of asphalt pavement when damaged by water is usually evaluated by the Marshall test. In this study, the Marshall stability and flow value of asphalt mixtures were tested on the basis of JTG E20 [19]. Cylindrical specimens $(101.6 \mathrm{~mm} \pm 0.2 \mathrm{~mm}$ in diameter and $63.5 \mathrm{~mm} \pm 1.3 \mathrm{~mm}$ high) were prepared. Three parallel samples were prepared for each asphalt mixture, and those specimens were subjected to a compressive load at a rate of $50 \mathrm{~mm} / \mathrm{min}$. The Marshall stability is the load that must be applied to cause the specimen to fail, and the flow value refers to the vertical deformation of the asphalt mixture specimen when it reaches the failure point when the asphalt mixture specimen is compressed. The retained stability $\left(\mathrm{MS}_{0}\right)$ is defined as follows:

$$
\mathrm{MS}_{0}=\frac{\mathrm{MS}_{1}}{\mathrm{MS}_{2}} \times 100
$$

where $\mathrm{MS}_{1}$ is the stability of the test specimen after $48 \mathrm{~h}$ of immersion in water at $60^{\circ} \mathrm{C}$ and $\mathrm{MS}_{2}$ is the stability of the test specimen after $0.5 \mathrm{~h}$ of immersion in water at $60^{\circ} \mathrm{C}$.

3.10. Freeze-Thaw Splitting Test. A freeze-thaw cycle was applied to simulate the actual situation affected by water during the road service process. According to JTG E20 [19], cylindrical specimens $(101.6 \mathrm{~mm} \pm 0.2 \mathrm{~mm}$ in diameter and $63.5 \mathrm{~mm} \pm 1.3 \mathrm{~mm}$ high) were prepared. Three parallel samples were prepared for each asphalt mixture. The Marshall specimens were kept in water under vacuum conditions for $15 \mathrm{~min}$, and then the specimens were frozen for $16 \mathrm{~h}$ at $-18^{\circ} \mathrm{C}$. After that, the specimens were immersed in water at $60^{\circ} \mathrm{C}$ for $24 \mathrm{~h}$. Finally, the specimens were kept in water at $25^{\circ} \mathrm{C}$ for $2 \mathrm{~h}$. The tensile strength ratio (TSR) is calculated as follows:

$$
\mathrm{TSR}=\frac{\bar{R}_{T 2}}{\bar{R}_{T 1}} \times 100,
$$

where $\bar{R}_{T 1}$ is the splitting strength before freezing and thawing and $\bar{R}_{T 2}$ is the splitting strength after freezing and thawing.

\section{Results and Discussion}

4.1. Segregation Test Results. The segregation test results are shown in Table 7. As seen from Table 7, compared with each modified asphalt, the segregation degree of the nanocarbonmodified asphalt after surface modification is the smallest, 
indicating that the nanocarbon treated with titanate coupling agent has the best compatibility with base asphalt. The difference in the softening point between the upper part and the lower part of the rubber powder-modified asphalt is 1.8, which indicates that the rubber powder and base asphalt have poor compatibility. However, compared with rubber powder-modified asphalt, the difference in the softening point between nanocarbon/rubber powder-modified asphalt and nanocarbon/copolymer SBS/rubber powder-modified asphalt decreases by $27.8 \%$ and $55.6 \%$, respectively. The results show that the compatibility between the rubber powder and base asphalt is improved by the addition of nanocarbon, and the segregation degree is further improved when the base asphalt is modified with three modifiers.

4.2. Conventional Physical Properties. The conventional physical index of each asphalt mixture is shown in Figure 3. The results indicate that the performance of each modified asphalt is improved compared with that of the base asphalt. After the surface modification of TMC931, the nanocarbonmodified asphalt substantially improves various indicators, indicating that the titanate coupling agent helps us to enhance the interaction between the nanoparticles and the base asphalt. In particular, the physical properties of nanocarbon/copolymer SBS/rubber powder composite-modified asphalt are the best.

As presented in Figure 3(a), the ductility of nanocarbon/ copolymer SBS/rubber powder-modified asphalt at $5^{\circ} \mathrm{C}$ is $16.50 \mathrm{~cm}$, which is $166.1 \%, 122.9 \%, 150.0 \%$, and $16.2 \%$ higher than that of the base asphalt, nanocarbon (after surface modification)-modified asphalt, rubber powder/ modified asphalt, and nanocarbon/rubber-modified asphalt, respectively. According to Figure 3(b), nanocarbon/copolymer SBS/rubber powder composite-modified asphalt has the highest softening point. Penetration is an index that indicates the softness and consistency of asphalt, reflecting the relative viscosity of asphalt under certain conditions. As shown in Figure 3(c), the nanocarbon/copolymer SBS/ rubber powder composite-modified asphalt has the lowest penetration, indicating that it is more viscous, which is conducive to mechanical construction. The penetration index reflects the temperature susceptibility of asphalt. From Figure 3(d), nanocarbon (after surface modification), rubber powder, nanocarbon/rubber powder, and nanocarbon/SBS/ rubber powder composite-modified asphalt result in increases of $49.6 \%, 46.4 \%, 180.8 \%$, and $196.8 \%$, respectively, in the penetration index compared to the base asphalt. Mo et al. indicated that during the high-speed shearing process, rubber powder and SBS particles undergo a swelling reaction, which absorbs the light components in the asphalt and increases the adhesion between the asphalt molecules [14]. In addition, nanocarbon particles with small particle diameters and large specific surface areas can increase the friction between the SBS, rubber powder, and base asphalt.

\subsection{Dynamic Shear Rheometer (DSR) Test}

4.3.1. Strain Sweep. To ensure the accuracy of the test results, it is necessary to determine the linear viscoelastic range of the base asphalt and modified asphalt through a strain sweep test, that is, the strain area when the complex shear modulus is reduced to $95 \%$ of the initial value [27]. The strain sweep results for the base asphalt and modified asphalt are shown in Figures 4 and 5 . The test results show that as the shear strain increases, the complex shear modulus of each asphalt specimen gradually increases, while the phase angle gradually decreases. Compared with the base asphalt, the composite shear modulus of the modified asphalt is higher and the phase angle is smaller; therefore, the addition of modifiers improves the strain sensitivity of the base asphalt. Under external loads, modified asphalt demonstrates a higher deformation resistance. To ensure the accuracy of subsequent tests, the strain of the temperature sweep and frequency sweep needs to be controlled within the range of viscoelasticity. Under low strain, the DSR test has accurate results, and combined with the original data, the strain of the temperature sweep and frequency sweep is controlled at $2 \%$.

4.3.2. Temperature Sweep. As presented in Figures 6 and 7, the test results indicate that modified asphalt binders show an increase in the complex shear modulus and a decrease in the phase angle compared to base asphalt at the same temperature. In other words, it is demonstrated that compared with nanomodified asphalt, base asphalt is more prone to large deformation under a high-temperature environment. In addition, the modification effect is ranked as nanocarbon/copolymer SBS/rubber powder > nanocarbon/ rubber powder $>$ rubber powder $>$ modified nanocarbon $>$ unmodified nanocarbon.

In the process of deformation, viscoelastic materials will produce elastic and viscous deformations. Elastic deformation can store energy; in viscoelastic mechanics, this energy is called the storage modulus $\left(G^{\prime}\right)$, the work of viscous deformation needs to overcome friction, and the final energy will be lost in the form of heat, so this part of the lost energy is called the loss modulus $\left(G^{\prime \prime}\right)$, while the loss factor is the ratio of $G^{\prime \prime}$ to $G^{\prime}$ [28]. Figure 8 shows that as the temperature increases, the loss factor of each asphalt mixture gradually increases. It can be explained that the increase in temperature greatly increases the mobility of asphalt molecules, so the energy loss also increases. Comparing modified asphalt and base asphalt at the same temperature, the loss factor of the modified asphalt is lower than that of the base asphalt. This is because the modifier and asphalt form a stable skeleton structure, which restricts the thermal movement of asphalt molecules in high-temperature environments.

4.3.3. Frequency Sweep. The simulation of road driving conditions can be achieved through frequency sweep tests $[29,30]$. The frequency sweep results of the asphalt binder at $60^{\circ} \mathrm{C}$ are shown in Figures 9-11.

Figures 9 and 10 show that as the frequency increases, the complex shear modulus gradually increases, while the phase angle changes with the opposite trend. As the frequency increases, the ratio of the elastic deformation of each asphalt mixture to the total deformation increases, so its 
TABLE 7: Results of the segregation test.

\begin{tabular}{lccc}
\hline Asphalt type & Upper softening point $\left({ }^{\circ} \mathrm{C}\right)$ & Lower softening point $\left({ }^{\circ} \mathrm{C}\right)$ & Difference $\left({ }^{\circ} \mathrm{C}\right)$ \\
\hline $\mathrm{NcPb}$ MA & 50.0 & 50.6 & 0.6 \\
$\mathrm{NcPa}$ MA & 56.9 & 57.2 & 0.3 \\
$\mathrm{RP}$ MA & 62.9 & 64.7 & 1.8 \\
$\mathrm{NcPa}-\mathrm{RP}$ MA & 69.8 & 71.1 & 1.3 \\
$\mathrm{NcPa}-\mathrm{SBS}-\mathrm{RP}$ MA & 76.3 & 77.1 & 0.8 \\
\hline
\end{tabular}

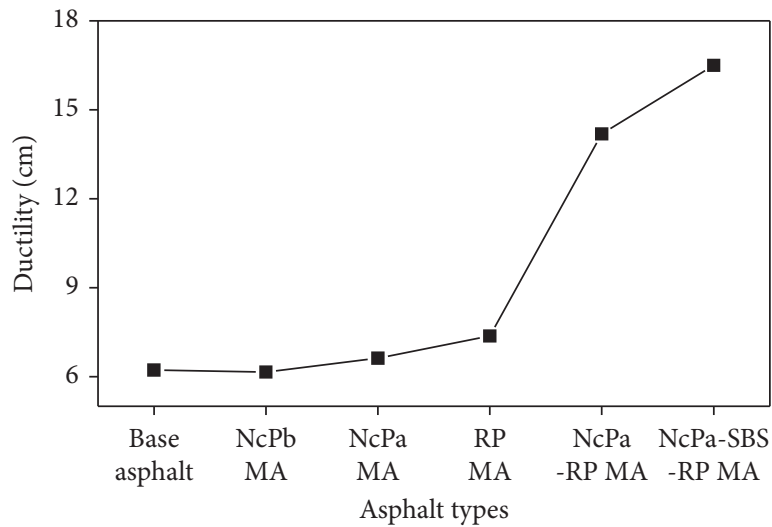

(a)

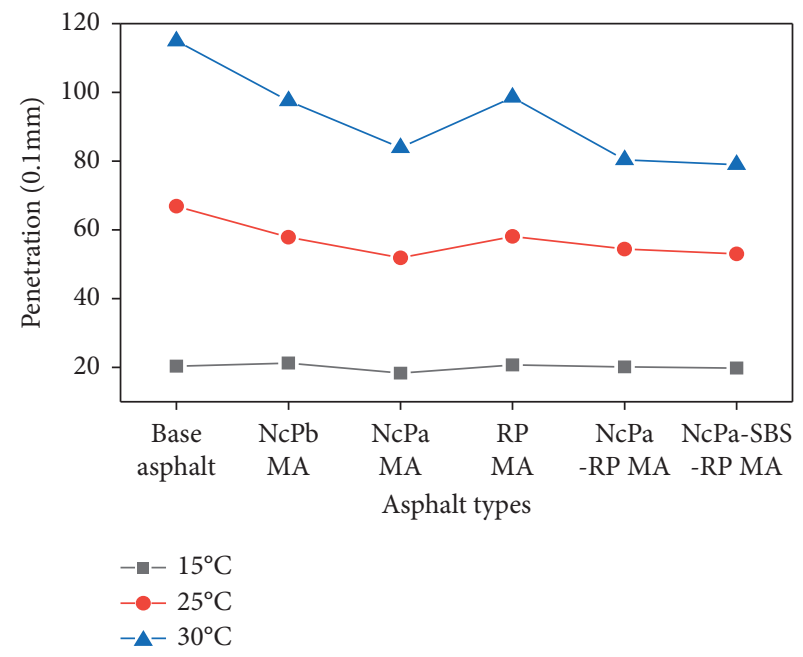

(c)

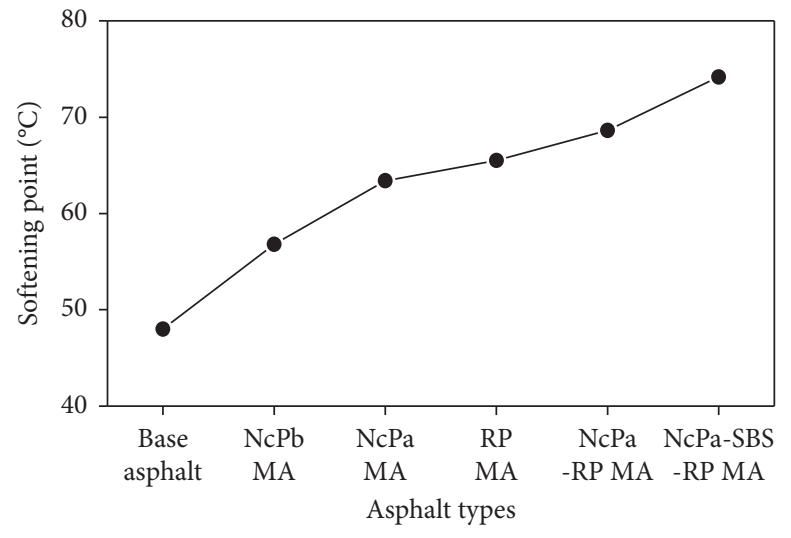

(b)

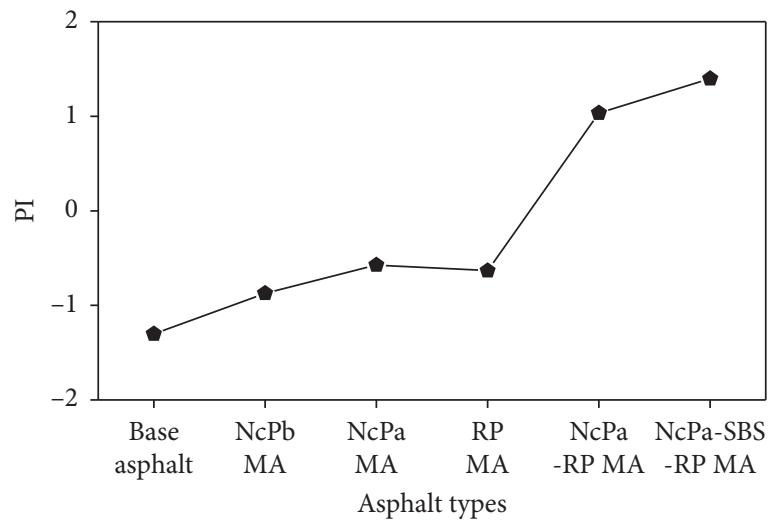

(d)

Figure 3: Regular physical index of each asphalt sample. (a) Ductility at $5^{\circ} \mathrm{C}$. (b) Softening point. (c) Penetration at $15^{\circ} \mathrm{C}, 25^{\circ} \mathrm{C}$, and $30^{\circ} \mathrm{C}$. (d) PI index.

ability to resist permanent deformation increases. This can be explained by the increase in frequency; that is, as the time the load acts on the asphalt material is reduced, the deformation of asphalt binders is reduced, which comprehensively demonstrates that the asphalt has a strong resistance to permanent deformation when the vehicle is traveling at a high speed. For the base asphalt, at $0.1 \mathrm{rad} / \mathrm{s}$, its phase angle is close to $90^{\circ}$, indicating that it is close to a viscous fluid state at this time. At the same frequency, the complex shear modulus of nanocarbon powder/copolymer SBS/rubber powder composite-modified asphalt is the highest, and the phase angle is the smallest.
As presented in Figure 11, as the frequency increases, the loss factor of each asphalt binder gradually decreases. In addition, at the same frequency, the loss factor of the modified asphalt is lower than that of the base asphalt, and the loss factor of nanocarbon powder/SBS rubber powder composite-modified asphalt is the smallest, indicating that the spatial structure formed by the three modifiers is the strongest when used in combination.

4.4. Bending Beam Rheometer (BBR) Test. The creep stiffness $(S)$ and creep rate $(m)$ at $-18^{\circ} \mathrm{C}$ are shown in Figure 12. As 


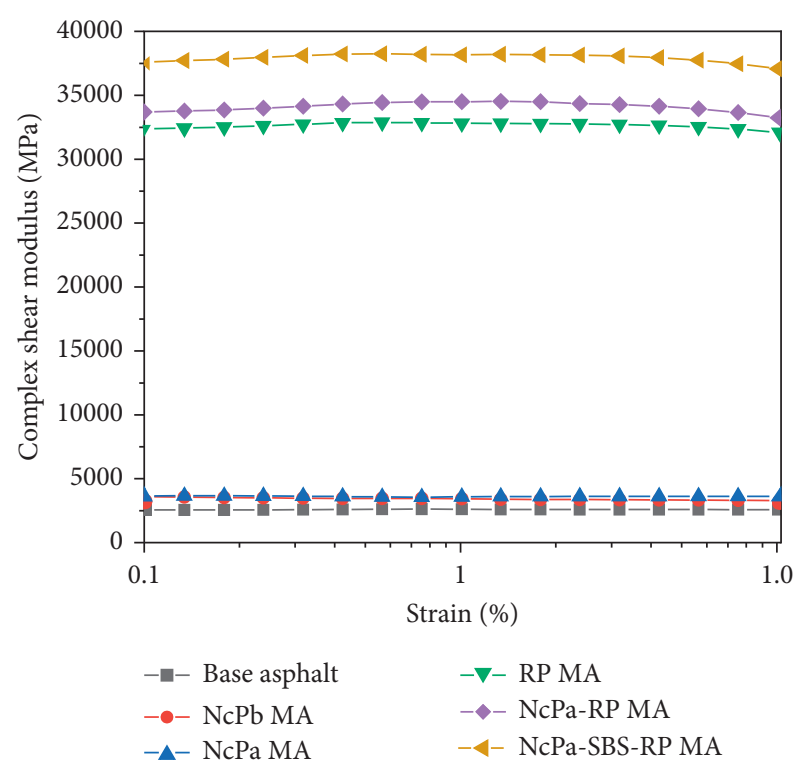

Figure 4: Complex shear modulus versus strain.

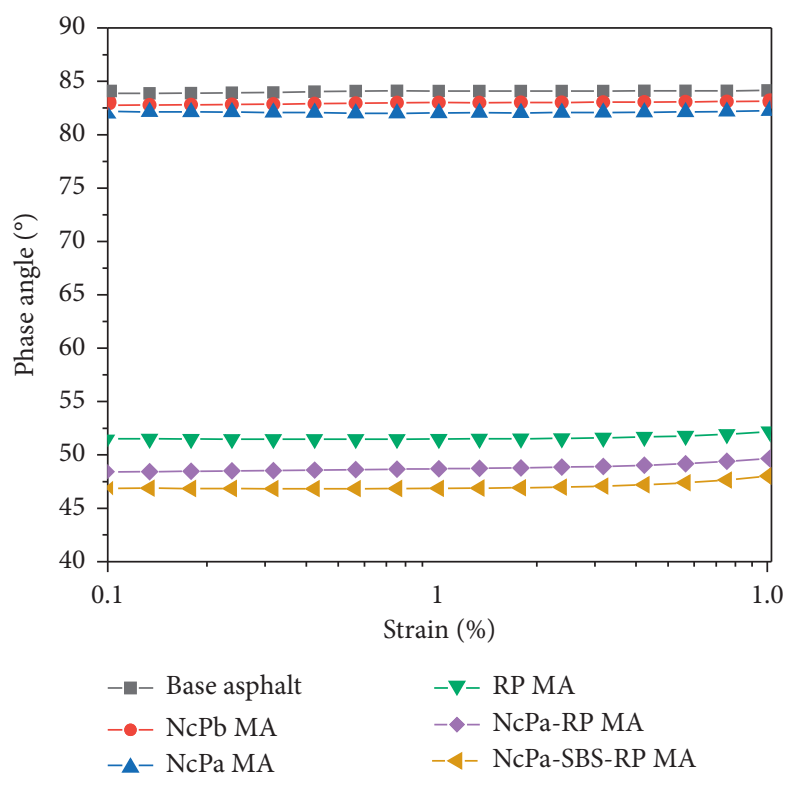

Figure 5: Phase angle versus strain.

presented in Figure 12(a), the creep stiffness of the modified asphalt is substantially lower than that of the base asphalt, indicating that the deformation resistance of the modified asphalt is better than that of the base asphalt. This is because the modified material increases the frictional resistance encountered during the movement of asphalt molecules, so the energy consumption is smaller. According to Figure 12(b), the creep rate of modified asphalt increases to different degrees compared with the base asphalt, which shows that after modification, asphalt has better relaxation ability, the force required to produce the same deformation is greater, and the crack resistance is improved. In addition, the modified effect of surface-modified nanocarbon particles is better than that of unmodified nanocarbon particles, and

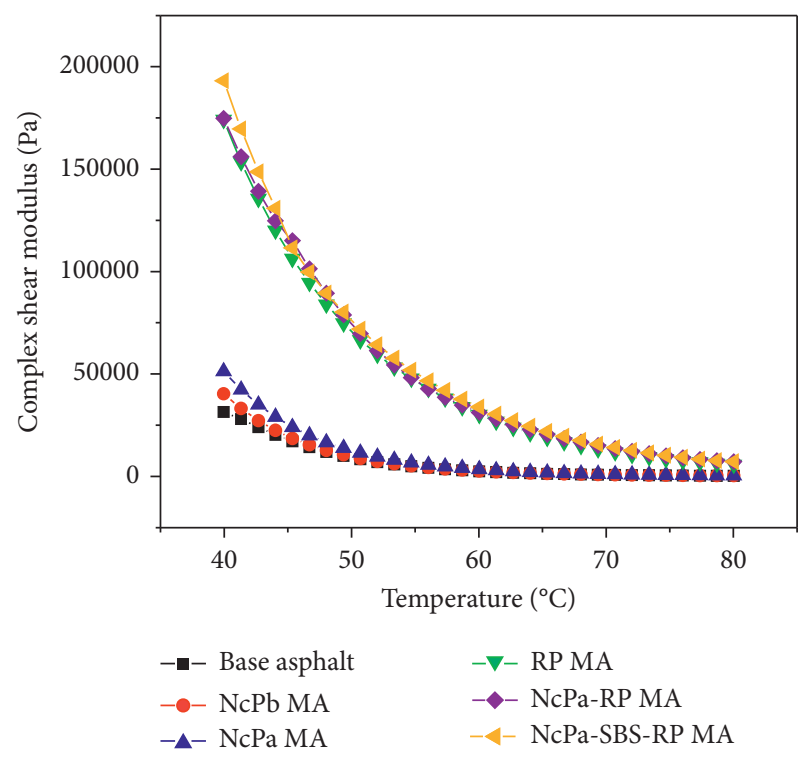

Figure 6: Complex shear modulus versus temperature.

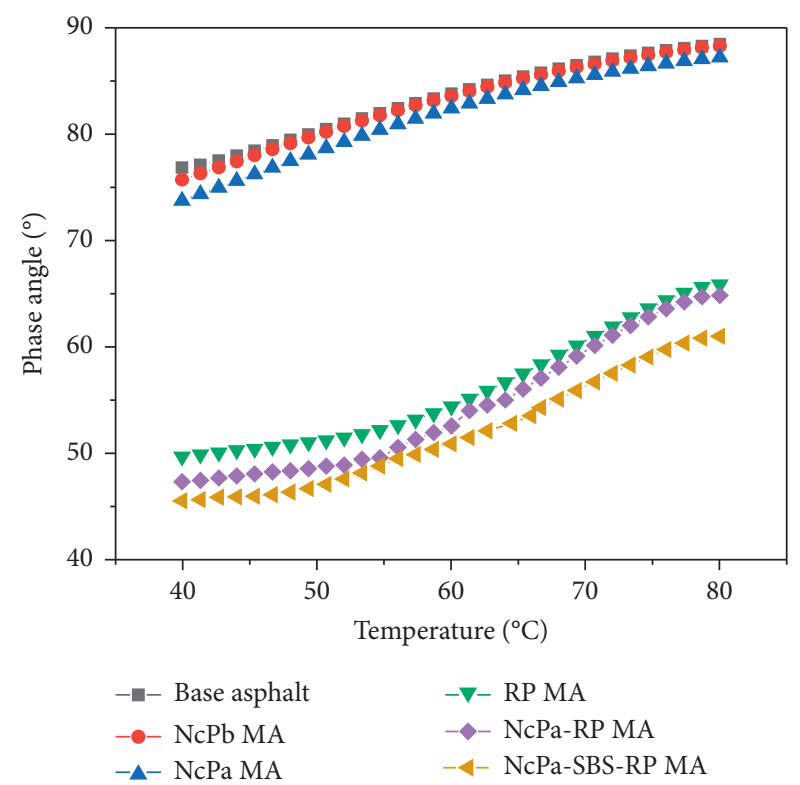

FIgURE 7: Phase angle versus temperature.

rubber powder modifier shows a more positive modification effect than nanocarbon particles. Compared with other modified asphalts, the creep stiffness $(S)$ of nanocarbon/ copolymer SBS/rubber powder-modified asphalt decreases by $41.9 \%$ compared with the base asphalt, and the creep rate ( $m$ ) increases by $11.7 \%$, which exhibits the best low-temperature crack resistance.

\subsection{Mechanism of Nanocarbon/SBS/Rubber Powder-Modified Asphalt}

4.5.1. Micromorphology. The macroscopic properties of asphalt are closely related to its microstructure [31]. The 


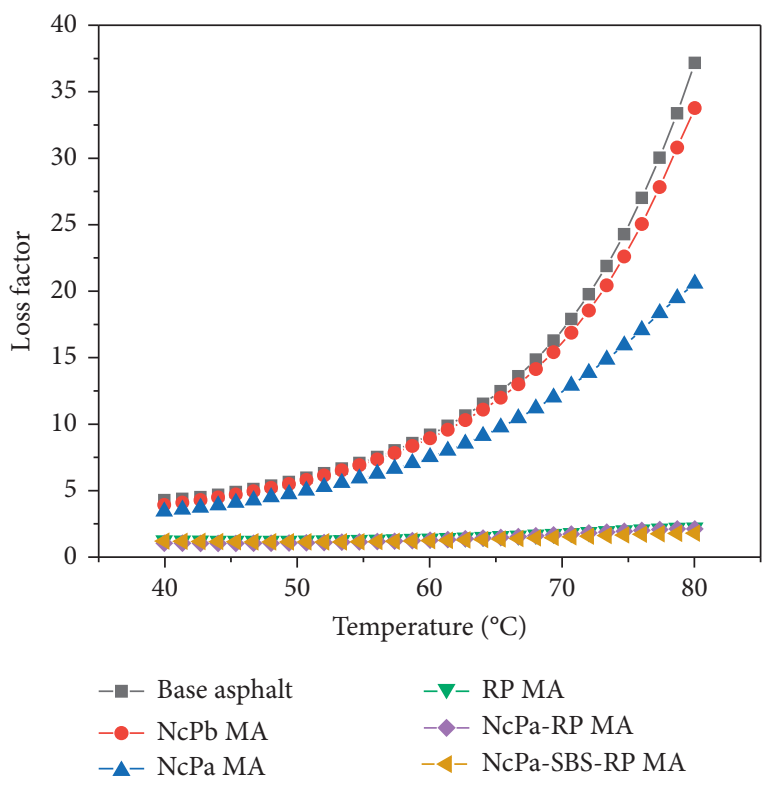

Figure 8: Loss factor versus temperature.

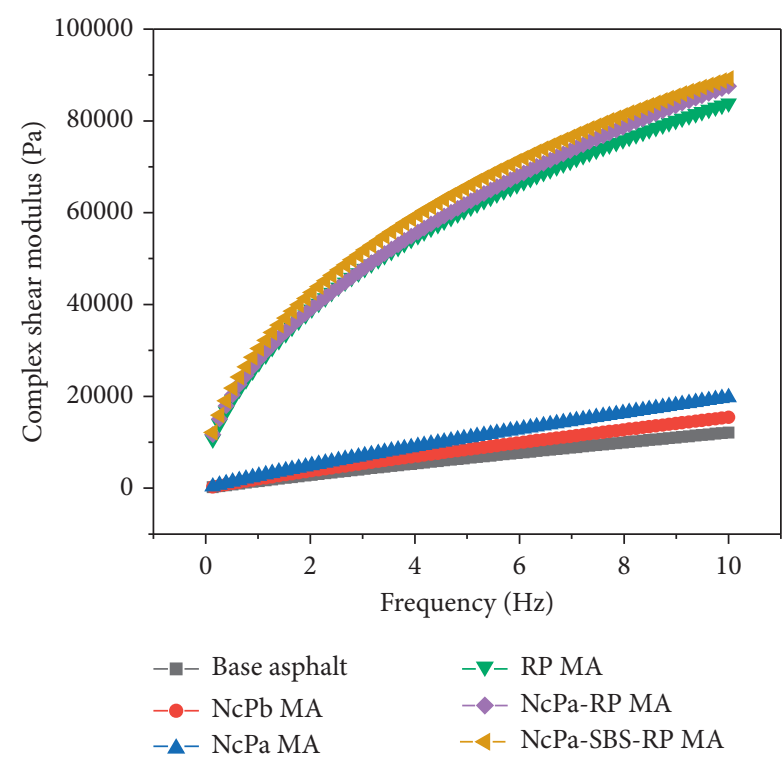

Figure 9: Complex shear modulus versus frequency.

microstructure of the base and modified asphalt can be observed by SEM. The results are shown in Figure 13.

As presented in Figure 13(a), the unmodified nanocarbon particles have a large amount of agglomeration, the particles are stacked on each other, and few individual particles appear, which is almost flocculent, verifying that the nanoparticles have high surface polarity. Figure 13(b) shows that the nanoparticles modified by the coupling agent solution are uniformly dispersed, the mass agglomeration phenomenon is obviously reduced, and the diffusion is effectively improved. This is because a molecular coating layer is formed on the surface of the carbon particles, which greatly reduces the surface polarity and weakens the

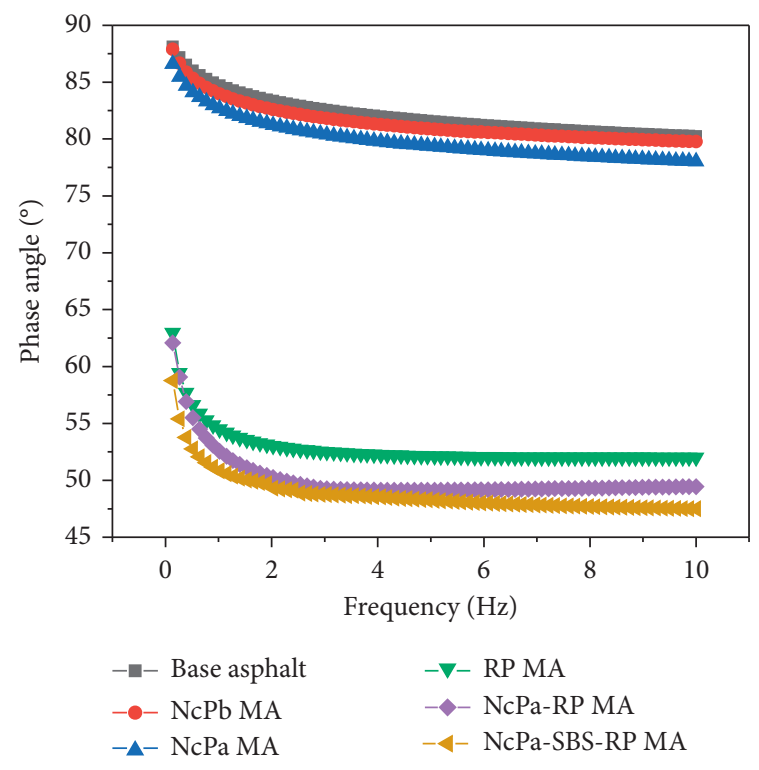

Figure 10: Phase angle versus frequency.

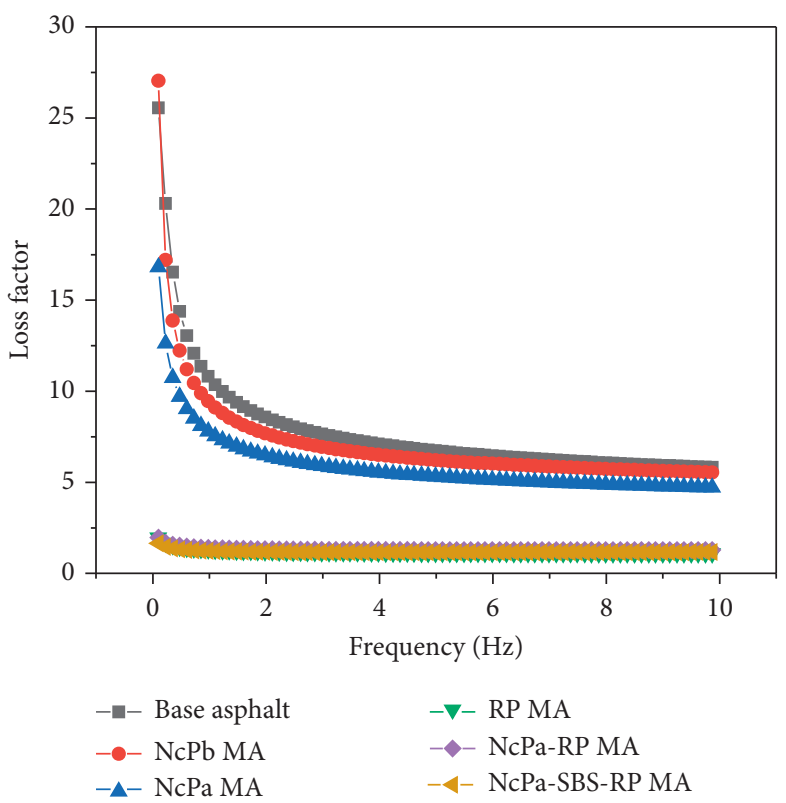

FIgURE 11: Loss factor versus frequency.

cohesion between the nanoparticles. Therefore, the performance of nanocarbon powder-modified asphalt after surface modification is better than that of nanomodified asphalt before modification.

Figure 13(c) shows that the surface of the base asphalt is smooth and free of impurities, presenting a uniform continuous phase. The micromorphology of rubber powdermodified asphalt is shown in Figure 13(d). The rubber particles are nested in the asphalt section, the appearance is uneven, and the surroundings are covered with a thicker asphalt layer. This is due to the swelling reaction between the rubber particles and the asphalt during the preparation process to absorb a large amount of light components in the 


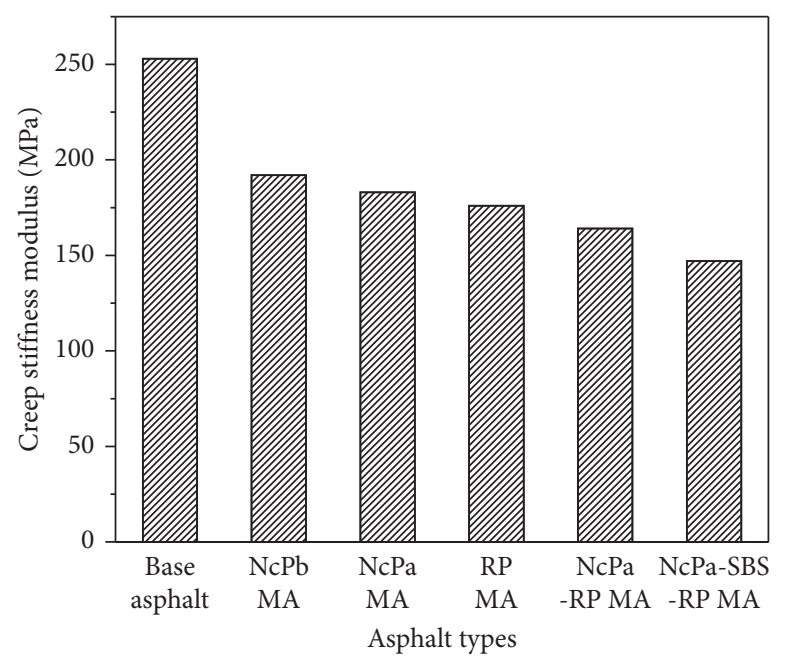

(a)

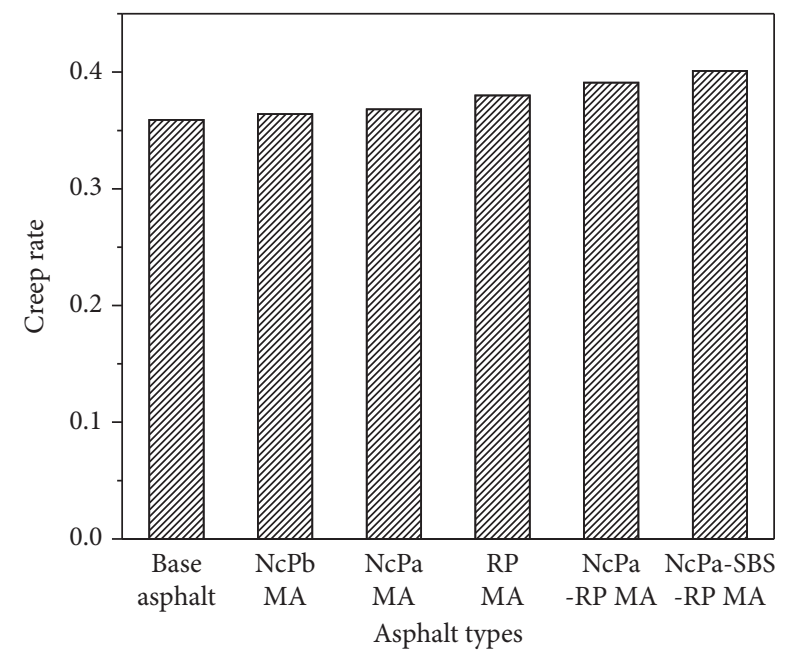

(b)

FIgURE 12: BBR test results of asphalt. (a) Creep stiffness of asphalt (b) Creep rate of asphalt.

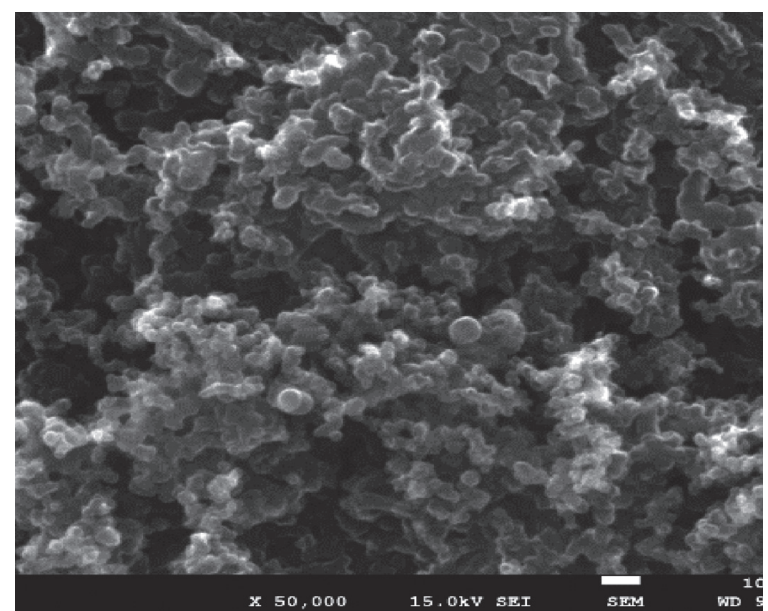

(a)

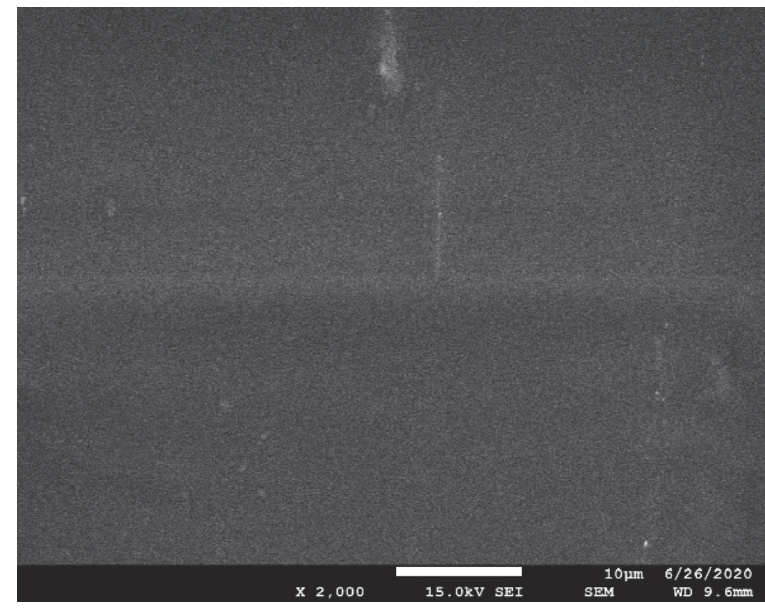

(c)

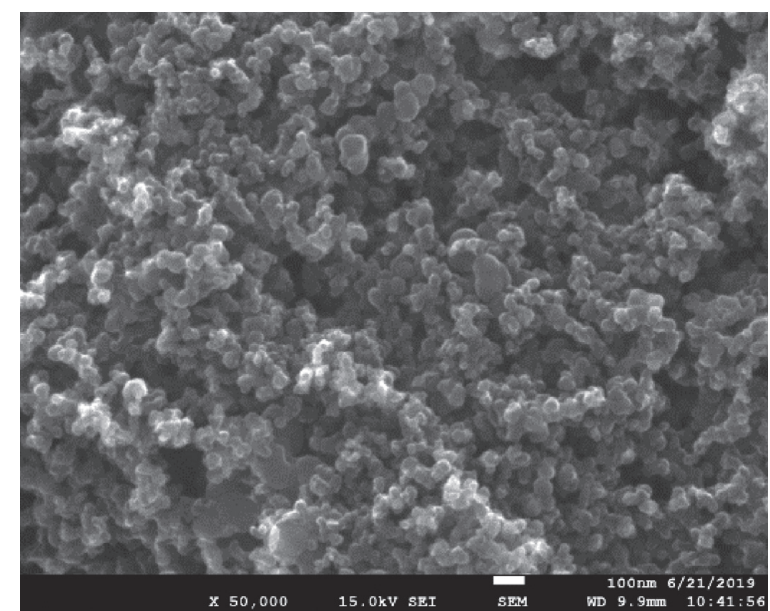

(b)

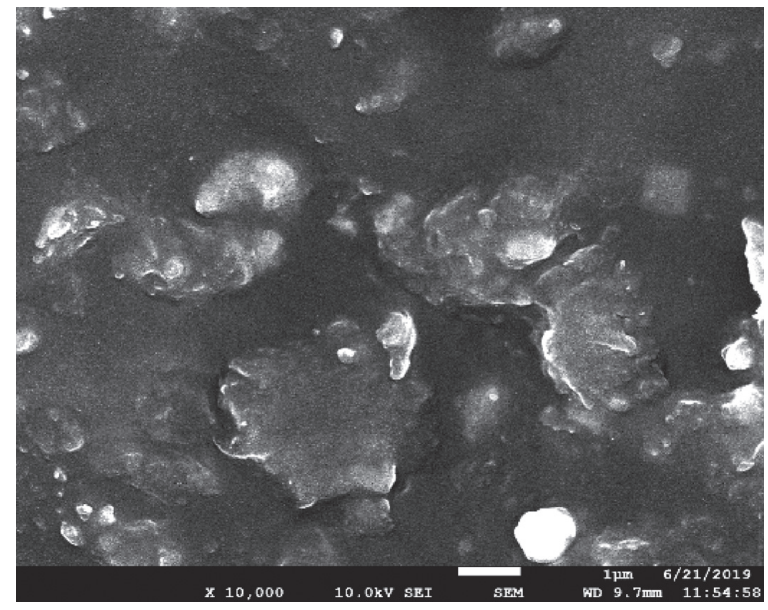

(d)

Figure 13: Continued. 


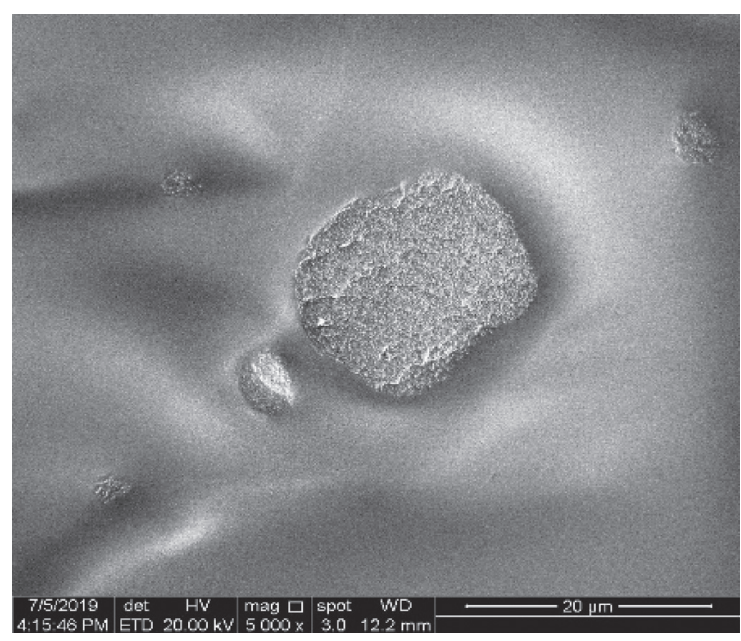

(e)

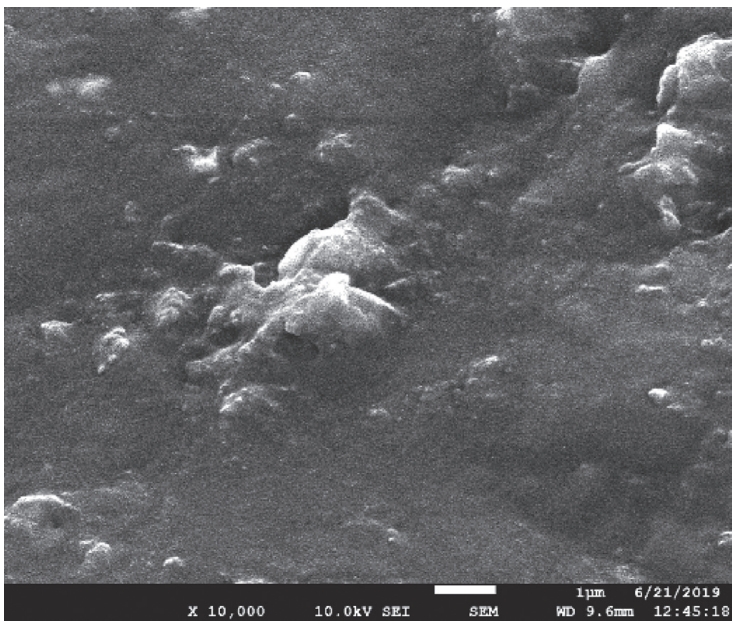

(g)

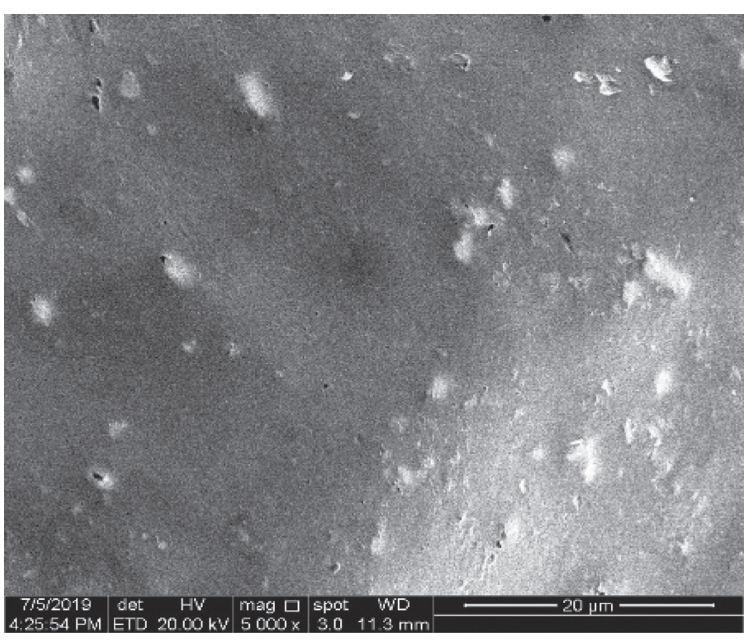

(f)

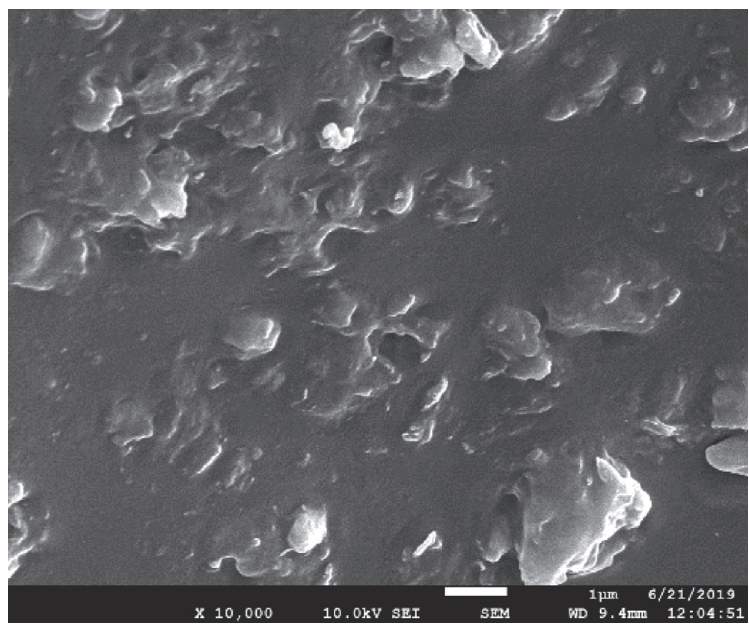

(h)

Figure 13: SEM images of the base asphalt and modified asphalt. (a) Nanocarbon particles (before surface modification). (b) Nanocarbon particles (after surface modification). (c) Base asphalt. (d) Rubber powder-modified asphalt. (e) Nanocarbon (before surface modification)modified asphalt. (f) Nanocarbon (after surface modification)-modified asphalt. (g) Nanocarbon/rubber powder-modified asphalt. (h) Nanocarbon/SBS/rubber powder-modified asphalt.

asphalt, which enhances the viscoelastic properties of asphalt. However, the rubber particles and the base asphalt are not completely bonded together, and the rubber-modified asphalt interface is weak. This is because the rubber powder after shearing is still irregularly shaped micron particles, and the contact area with the asphalt is relatively small. There is no other material with a smaller particle size to compensate for the small voids generated on the interface, and it is difficult to form an effective transition on the contact surface.

As shown in Figure 13(e), unmodified carbon powder particles are severely agglomerated in the pitch because the polar particles of the nanocarbon particles are difficult to disperse in the asphalt medium of nonpolar materials. As shown in Figure 13(f), the nanoparticles modified by the titanate coupling agent solution can be evenly distributed in the asphalt. It is obvious that the surface is covered with a thin layer of asphalt, which wraps the carbon particles and achieves a good dispersion effect. This is because one end of the titanate coupling agent molecule is attached to the surface of the nanoparticles, reducing the surface energy, and the other end is combined with the asphalt to promote the formation of a stable structure between the nanoparticles and the base asphalt.

Figure $13(\mathrm{~g})$ shows that the contact surface between the rubber particles and the base asphalt becomes blurred, indicating that the nanocarbon improves the bonding effect of the rubber powder and the asphalt interface. As presented in Figure 13(h), the structural skeleton of the nanocarbon/ copolymer SBS/rubber powder composite-modified asphalt is clearer, and the interface transition between the modifier and the asphalt is smoother, forming a relatively continuous structural system with a relatively continuous particle size, which effectively ensures that the load force is evenly transmitted between the particles and makes the overall network structure of the composite-modified asphalt more 
stable. Therefore, nanocarbon/copolymer SBS/rubber powder composite-modified asphalt has excellent conventional physical properties and rheological properties.

4.5.2. FTIR. Through the infrared spectroscopy analysis of the base asphalt and modified asphalt, the modification mechanism of each modifier on the base asphalt was analyzed from a chemical point of view. Referring to the existing research results [32], the common characteristic peaks in asphalt are analyzed, and the strong peaks within the $2800-3000 \mathrm{~cm}^{-1}$ region are the typical C-H vibrations of cycloalkanes and alkanes. Among them, $-\mathrm{CH}_{2}-$ has the strongest ability to absorb infrared radiation, so the strong peaks at approximately $2854 \mathrm{~cm}^{-1}$ and $2924 \mathrm{~cm}^{-1}$ are typical $\mathrm{C}-\mathrm{H}$ stretching vibrations in aliphatic chains. The conjugated $\mathrm{C}=\mathrm{C}$ double bond is at $1602 \mathrm{~cm}^{-1}$. The strong absorption peaks at $1457 \mathrm{~cm}^{-1}$ and $1377 \mathrm{~cm}^{-1}$ are the stretching vibrations of the asymmetric bond of $\mathrm{C}-\mathrm{CH}_{3}$ and the symmetric bond of $-\mathrm{CH}_{2}-$.

As shown in Figure 14, compared with the base asphalt, the spectrum of rubber powder-modified asphalt shows no substantial change, only in the peak strength, and there is no new absorption peak in the whole functional group area. It is inferred that there is no chemical reaction between the rubber powder and base asphalt, indicating that the physical reaction plays the primary role between the rubber powder and base asphalt, which is consistent with He's research conclusions [14]. Comparing the spectrum of the base asphalt, it can be seen from Figure 15 that there is no new absorption peak in the spectrum of the unmodified nanocarbon-modified asphalt, while the surface-modified nanocarbon-modified asphalt has a new absorption peak at $1259 \mathrm{~cm}^{-1}$. This is because the modified nanocarbon and asphalt macromolecule chemical bonds are generated by the rupture of unsaturated bonds, and free radical groups undergo a chemical reaction, indicating that after surface modification by the coupling agent, both a chemical reaction and a physical reaction occur between the nanocarbon and the base asphalt. Figure 16 shows that the combined use of several modifiers does not produce a new absorption peak, except for the characteristic peak of copolymer SBS at $699 \mathrm{~cm}^{-1}$ and butadiene at $966 \mathrm{~cm}^{-1}$, which is only a difference in transmission [33]. The slight changes in the other peak wave positions are caused by free radicals generated by the breakage of a small amount of polymer macromolecules during the highspeed shearing of rubber powder and SBS particles. This demonstrates that there is no chemical reaction between the three modifiers but a simple physical blending.

4.6. Asphalt Mixture Performance. Asphalt mixtures are multiphase composite materials composed of asphalt, mineral powder, aggregates, voids, etc. As an important part of asphalt mixtures, asphalt has a substantial impact on the performance of asphalt mixtures. Research on the moisture stability, rutting resistance, and low-temperature crack resistance of nanocarbon/copolymer SBS/rubber powder composite-modified asphalt mixtures is performed in this section.

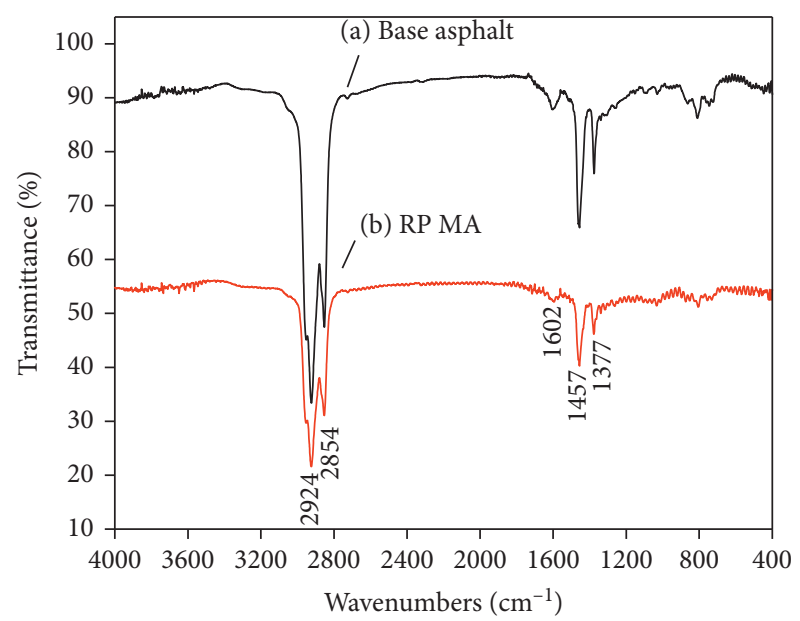

FIGURE 14: FTIR spectra of the base asphalt and rubber powdermodified asphalt.

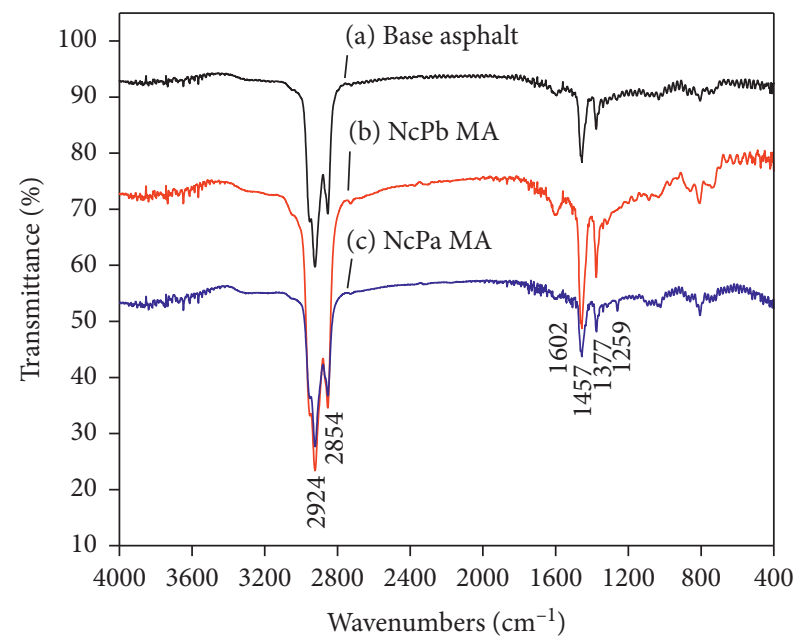

FIGURE 15: FTIR spectra of the base asphalt and nanocarbonmodified asphalt.

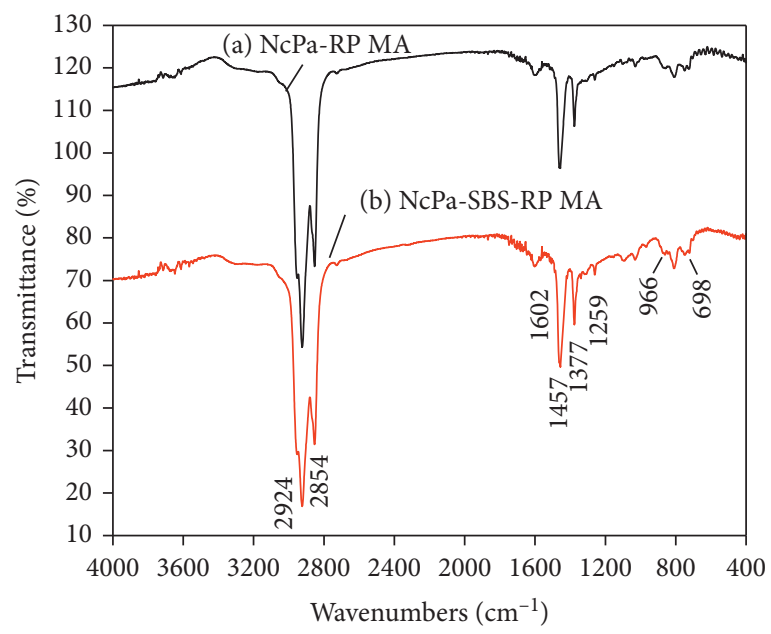

FIGURE 16: FTIR spectra of the nanocarbon/rubber powdermodified asphalt and nanocarbon/SBS/rubber powder-modified asphalt. 
TABLE 8: Results of the rutting test.

\begin{tabular}{lccc}
\hline \multirow{2}{*}{ Asphalt mixture } & \multicolumn{2}{c}{ Deformation $(\mathrm{mm})$} & ${\text { Dynamic stability }\left(\text { times } \mathrm{mm}^{-1} \text { ) }\right.}$ \\
\hline Base asphalt & $45 \mathrm{~min}$ & $60 \mathrm{~min}$ & 1874 \\
Nanocarbon & 3.652 & 3.988 & 2957 \\
Rubber powder & 2.144 & 2.357 & 2864 \\
Nanocarbon/rubber powder & 2.285 & 2.505 & 3728 \\
Nanocarbon/SBS/rubber powder & 1.685 & 1.854 & 5581 \\
\hline
\end{tabular}

TABle 9: Results of the low-temperature trabecular bending test.

\begin{tabular}{lccc}
\hline Asphalt mixture & Flexural tensile strain $(\mathrm{MPa})$ & Flexural strength $(\mu \varepsilon)$ & Flexural stiffness modulus $(\mathrm{MPa})$ \\
\hline Base asphalt & 7.53 & 2518 & 2990 \\
Nanocarbon & 8.01 & 2850 & 2810 \\
Rubber powder & 10.24 & 3590 & 2902 \\
Nanocarbon/rubber powder & 10.67 & 3816 & 2796 \\
Nanocarbon/SBS/rubber powder & 12.41 & 4795 & 2588 \\
\hline
\end{tabular}

TABLE 10: Results of the immersion Marshall test.

\begin{tabular}{lccccc}
\hline \multirow{2}{*}{ Asphalt mixture } & \multicolumn{2}{c}{ Soaked for $0.5 \mathrm{~h}$} & \multicolumn{2}{c}{ Soaked for $48 \mathrm{~h}$} & Retained stability $(0.1 \mathrm{~mm})$ \\
& Stability $(\mathrm{kN})$ & Flow value $(0.1 \mathrm{~mm})$ & Stability $(\mathrm{kN})$ & Flow value $(0.1 \mathrm{~mm})$ & 81.5 \\
Base asphalt & 9.2 & 29.7 & 7.5 & 35.2 & 87.7 \\
Nanocarbon & 10.6 & 28.6 & 9.3 & 33.6 & 84.7 \\
Rubber powder & 11.8 & 28.8 & 10.0 & 32.7 & 88.4 \\
Nanocarbon/rubber powder & 12.3 & 27.8 & 10.9 & 31.5 & 90.3 \\
Nanocarbon/SBS/rubber powder & 14.3 & 27.3 & 12.9 & 29.6 & \\
\hline
\end{tabular}

4.6.1. High-Temperature Stability. The rutting test is one of the most predominant methods to evaluate the antirutting performance of asphalt mixtures at high temperatures. The test results of all the asphalt mixtures are described in Table 8 . As presented in Table 8 , the dynamic stability of each modified asphalt mixture is higher than that of the base asphalt mixture, and the rutting depth is correspondingly smaller, indicating that the addition of modifiers can effectively improve the high-temperature rutting resistance of the asphalt mixture. Among them, nanocarbon-, rubber powder-, nanocarbon/rubber powder-, and nanocarbon/SBS/rubber powder-modified asphalt mixtures result in $57.8 \%, 52.8 \%, 98.9 \%$, and $198.0 \%$ increases in dynamic stability, respectively, compared to the base asphalt mixture. The results are attributed to the rubber powder and copolymer SBS undergoing a swelling reaction in the base asphalt, which enhances the bonding ability between the asphalt and the aggregates [14]. In addition, the nanocarbon particles have a small size, which can effectively fill the gaps between the mixtures, thereby improving the high-temperature rutting resistance of the asphalt mixture.

4.6.2. Low-Temperature Crack Resistance. A low-temperature trabecular bending test was conducted to discuss the low-temperature crack resistance of the mixture. The test results of low-temperature trabecular beams of various asphalt mixtures at $-10^{\circ} \mathrm{C}$ are shown in Table 9. The flexural tensile strain and flexural strength of the modified asphalt mixture are higher than those of the base asphalt mixture, and the flexural stiffness modulus is lower than that of the base asphalt mixture. In addition, the nanocarbon/SBS/rubber powder-modified asphalt mixture has the best low-temperature crack resistance. Yu et al. illustrated that SBS-modified asphalt has a three-dimensional spatial network structure, which can improve the anticracking performance of asphalt mixtures at low temperatures [34]. The addition of rubber powder makes the asphalt mixture have higher elastic energy storage, and the addition of nanocarbon particles enhances the bond between the asphalt and aggregates.

4.6.3. Moisture Stability. Moisture damage occurs when the adhesion and cohesion of the asphalt mixture is lost. The immersion Marshall test and freeze-thaw splitting test were carried out to demonstrate the moisture stability of the nanocarbon/copolymer SBS/rubber powder composite-modified asphalt mixture. The results of the immersion Marshall test and freeze-thaw splitting test are shown in Table 10 and 11 , respectively. To make the test results more intuitive, the retained stability and tensile strength ratio of each asphalt mixture are plotted in Figure 17.

Figure 17 shows that the retained stability and freeze-thaw splitting strength ratio of the modified asphalt mixture are higher than those of the base asphalt mixture, indicating that 
TABLE 11: Results of the freeze-thaw splitting test.

\begin{tabular}{lccc}
\hline Asphalt mixture & $\begin{array}{c}\text { Splitting strength before freezing and } \\
\text { thawing (MPa) }\end{array}$ & $\begin{array}{c}\text { Splitting strength after freezing and } \\
\text { thawing }(\mathrm{MPa})\end{array}$ & $\begin{array}{c}\text { Tensile strength ratio } \\
(\%)\end{array}$ \\
\hline $\begin{array}{l}\text { Base asphalt } \\
\text { Nanocarbon }\end{array}$ & 0.914 & 0.718 & 78.56 \\
$\begin{array}{l}\text { Rubber powder } \\
\text { Nanocarbon/rubber }\end{array}$ & 1.135 & 0.970 & 85.46 \\
$\begin{array}{l}\text { powder } \\
\text { Nanocarbon/SBS/rubber } \\
\text { powder }\end{array}$ & 1.084 & 0.891 & 82.20 \\
\hline
\end{tabular}

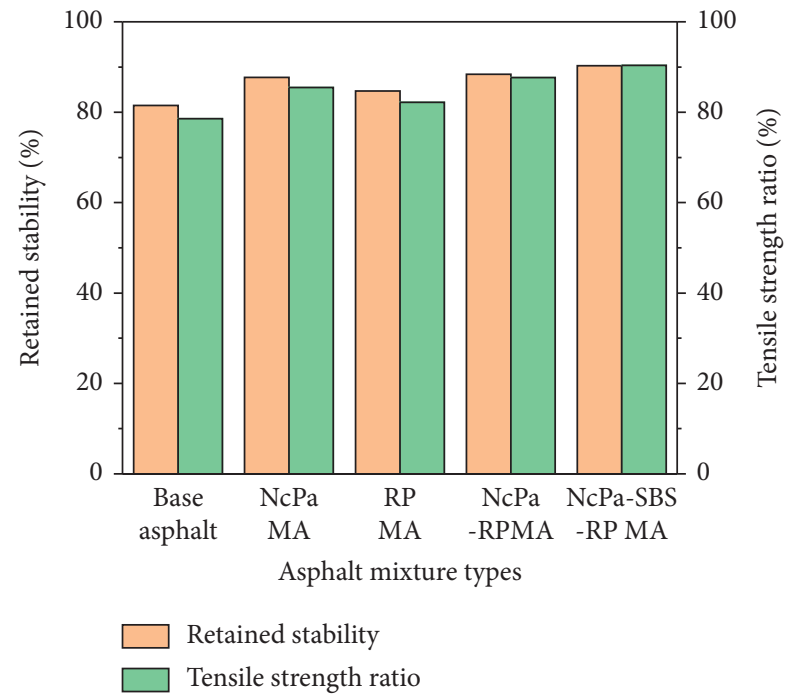

FIgURE 17: Results of the moisture stability test.

the addition of modifiers can effectively improve the moisture stability of the asphalt mixture. Among them, the nanocarbon/SBS/rubber powder composite-modified asphalt mixture has the best moisture resistance. The addition of SBS and rubber powder can enhance the strength of the interface between the asphalt and aggregates and can effectively resist water intrusion into the bonding interface [17]. The presence of nanocarbon particles makes the internal structure of the asphalt mixture more compact, so the moisture stability of the asphalt mixture is substantially improved.

\section{Conclusions}

The nanocarbon, copolymer SBS, and rubber powder were selected as modifiers to improve the properties of the $\mathrm{AH}-70$ asphalt and mixture. The effect of each modifier on the physical and rheological properties of the base asphalt was evaluated by ductility tests, softening tests, penetration tests, high-temperature dynamic shear rheological tests, and lowtemperature bending rheology tests. Each modifier mechanism of the composite-modified asphalt was analyzed by infrared spectroscopy and scanning electron microscopy tests. Various laboratory tests were implemented to evaluate the performance characteristics of modified and compositemodified asphalt mixtures. Based on the laboratory testing results, the following conclusions are drawn: (i) Compared with the unmodified nanocarbon particles, the surface-modified nanocarbon particles substantially increased the softening point and penetration index of the base asphalt and improved the ductility of the base asphalt. The segregation softening point difference in nanocarbon-modified asphalt (after surface modification-modified asphalt) was lower than that of the unmodified nanocarbon asphalt. Moreover, SEM analysis indicates that surface modification can substantially improve the compatibility of nanocarbon and asphalt.

(ii) Nanocarbon and rubber powder additives can improve the high-temperature performance of the base asphalt, with no obvious influence on the lowtemperature performance. Moreover, the addition of SBS can effectively improve the low-temperature performance of nanocarbon (after surface modification)/rubber powder-modified asphalt, as reflected in the high ductility value and creep rate. The dynamic shear rheometer test indicates that all of the modified asphalt present a higher complex shear modulus and lower phase angle and loss factor than the base asphalt. Furthermore, the nanocarbon/ copolymer SBS/rubber powder composite-modified asphalt exhibits the best physical and rheological properties among the four modification systems.

(iii) The micromorphology of all modified asphalt mixtures shows that the nanocarbon particles can increase the compatibility between the base asphalt and rubber powder, and then the addition of copolymer SBS can improve the structure of nanocarbon (after surface modification)/rubber powder-modified asphalt to form a stable network. The FTIR tests indicate that the physical reaction plays a dominant role in the modification process for the rubber powder-modified asphalt, and both physical reactions and chemical reactions mainly occur between the surface-modified nanocarbon particles and base asphalt.

(iv) Both the high-temperature stability and low-temperature cracking resistance of the nanocarbon/ copolymer SBS/rubber powder composite-modified asphalt mixture are approximately 1.3 times those of the nanocarbon/rubber powder asphalt mixture. Additionally, the nanocarbon/copolymer SBS/rubber powder composite-modified asphalt mixture has better moisture stability than all the other modified asphalt mixtures in this paper. 
The laboratory testing results demonstrate the superior properties of the nanocarbon/copolymer SBS/rubber powder composite-modified asphalt and nanocarbon/copolymer SBS/rubber powder composite-modified asphalt mixture. However, further research will be conducted with field testing and durability testing on such a mixture to verify the findings obtained from the laboratory study.

\section{Data Availability}

The data used to support the findings of this study are included within the article.

\section{Conflicts of Interest}

The authors declare no conflicts of interest.

\section{Acknowledgments}

The authors appreciate the financial support from the National Natural Science Foundation of China (Grant no. 51378474), Fund of Leading Talent in Science and Technology Innovation (Grant no. 194200510015), Science and Technology Department of Henan Province (Grant no. 192102310012), Key Project of Colleges and Universities of Henan Province (Grant no. 19A560024), and Fund of Zhengzhou University of Aeronautics Graduate Education Innovation Plan (Grant no. 2020CX35).

\section{References}

[1] P. L. Cong, X. Z. Guo, and L. N. Mei, "Investigation on rejuvenation methods of aged SBS modified asphalt binder," Fuel, vol. 11, p. 279, 2020.

[2] J. Liu, K. Z. Yan, W. Y. Liu, and X. W. Zhao, "Partially replacing Styrene-Butadiene-Styrene (SBS) with other asphalt binder modifier: feasibility study," Construction and Building Materials, vol. 14, p. 249, 2020.

[3] H.-L. Zhang, M.-M. Su, S.-F. Zhao, Y.-P. Zhang, and Z.-P. Zhang, "High and low temperature properties of nanoparticles/polymer modified asphalt," Construction and Building Materials, vol. 114, pp. 323-332, 2016.

[4] M. Zarei, Z. Rahmani, M. Zahedi, and M. Nasrollahi, "Technical, economic, and environmental investigation of the effects of rubber powder additive on asphalt mixtures," Journal of Transportation Engineering, vol. 146, no. 1, 2020.

[5] X. Tian, R. Zhang, Z. Yang, Y. Chu, Y. Xu, and Q. Zhang, "Multiscale study on the effect of nano-organic montmorillonite on the performance of rubber asphalt," Journal of Nanomaterials, vol. 2018, pp. 1-10, 2018.

[6] R. Li, F. Xiao, S. Amirkhanian, Z. You, and J. Huang, "Developments of nano materials and technologies on asphalt materials-a review," Construction and Building Materials, vol. 143, pp. 633-648, 2017.

[7] K. P. Murugan, M. Balaji, S. S. Kar, S. Swarnalatha, and G. Sekaran, "Nano fibrous carbon produced from chromium bearing tannery solid waste as the bitumen modifier," Journal of Environmental Management, vol. 14, p. 270, 2020.

[8] Q. Yang, X. Li, L. Zhang et al., "Performance evaluation of bitumen with a homogeneous dispersion of carbon nanotubes," Carbon, vol. 158, pp. 465-471, 2020.
[9] F. Xiao, A. N. Amirkhanian, and S. N. Amirkhanian, "Longterm ageing influence on rheological characteristics of asphalt binders containing carbon nanoparticles," International Journal of Pavement Engineering, vol. 12, no. 6, pp. 533-541, 2011.

[10] A. N. Amirkhanian, F. P. Xiao, and S. N. Amirkhanian, "Characterization of unaged asphalt binder with carbon nano particle," International Journal of Pavement Research and Technology, vol. 5, no. 5, pp. 281-286, 2010.

[11] F. Xiao, A. N. Amirkhanian, and S. N. Amirkhanian, "Influence of carbon nanoparticles on the rheological characteristics of short-term aged asphalt binders," Journal of Materials in Civil Engineering, vol. 23, no. 4, pp. 423-431, 2011.

[12] L. Sun, X. Xin, and J. Ren, "Asphalt modification using nanomaterials and polymers composite considering high and low temperature performance," Construction and Building Materials, vol. 133, pp. 358-366, 2017.

[13] R. He, S. H. Wu, X. F. Wang, Z. J. Wang, and H. X. Chen, "Temperature sensitivity characteristics of SBS/CRP-Modified bitumen after different aging processes," Materials, vol. 11, no. 11, 2018.

[14] L. Mo, D. Shu, X. Li, M. Huurman, and S. Wu, "Experimental investigation of bituminous plug expansion joint materials containing high content of crumb rubber powder and granules," Materials \& Design, vol. 37, pp. 137-143, 2012.

[15] Y. Tan, M. Guo, L. Cao, and L. Zhang, "Performance optimization of composite modified asphalt sealant based on rheological behavior," Construction and Building Materials, vol. 47, pp. 799-805, 2013.

[16] H. Zhang and M. Gong, "Study on durability of compositemodified asphalt mixture based on inherent and improved performance," Construction and Building Materials, vol. 179, pp. 539-552, 2018.

[17] H. T. Zhang, M. Y. Gong, D. D. Gao, T. Yang, and Y. L. Huang, "Comparative analysis of mechanical behavior of composite modified asphalt mixture based on PG technology," Construction and Building Materials, vol. 17, p. 259, 2020.

[18] X. Meng, X. B. Xie, G. H. Li, P. Zhang, P. Li, and W. H. Zhao, "Experimental study on preparation technology of nanocarbon particles/rubber powder composite modified asphalt based on orthogonal grey relation analysis," Bulletin of the Chinese Ceramic Society, vol. 38, no. 8, pp. 2642-2649, 2019, (in Chinese).

[19] China Communications Press, Standard Test Methods of Bitumen and Bituminous Mixtures for Highway Engineering, China Communications Press, Beijing, China, 2011, (in Chinese).

[20] M. R. M. Hasan, Z. P. You, M. K. I. M. Satar et al., "Effects of titanate coupling agent on engineering properties of asphalt binders and mixtures incorporating LLDPE-CaCO3 pellet," Applied Sciences, vol. 8, no. 7, 2018.

[21] J. Li, S. Yang, Y. Liu, Y. Muhammad, Z. Su, and J. Yang, "Studies on the properties of modified heavy calcium carbonate and SBS composite modified asphalt," Construction and Building Materials, vol. 218, pp. 413-423, 2019.

[22] H. Zhang, Y. Gao, G. Guo, B. Zhao, and J. Yu, "Effects of ZnO particle size on properties of asphalt and asphalt mixture," Construction and Building Materials, vol. 159, pp. 578-586, 2018.

[23] W. G. Zhang, L. T. Ding, and Z. R. Jia, "Design of SBSmodified bitumen stabilizer powder based on the vulcanization mechanism," Applied Sciences, vol. 8, no. 3, 2018. 
[24] ASTMD7175, Standard test method for determining the rheological properties of asphalt binder using a dynamic shear rheometer, 2015.

[25] AASHTOT313-12, Determining the Flexural Creep Stiffness of Asphalt Binder Using the Bending Beam Rheometer (BBR), American Association of State Highway and Transportation Officials, Washington, DC, USA, 2012.

[26] Z. Dong, T. Zhou, H. Luan, H. Wang, N. Xie, and G.-q. Xiao, "Performance evaluation of bio-based asphalt and asphalt mixture and effects of physical and chemical modification," Road Materials and Pavement Design, vol. 21, no. 6, pp. 1470-1489, 2020.

[27] G. H. Shafabakhsh and O. J. Ani, "Experimental investigation of effect of $\mathrm{Nano}_{\mathrm{TiO}} / \mathrm{SiO}_{2}$ modified bitumen on the rutting and fatigue performance of asphalt mixtures containing steel slag aggregates," Construction and Building Materials, vol. 98, pp. 692-702, 2015.

[28] M. A. Nazki, T. Chopra, and A. K. Chandrappa, "Rheological properties and thermal conductivity of bitumen binders modified with graphene," Construction and Building Materials, vol. 9, p. 238, 2020.

[29] H. Zhang, G. Xu, X. Chen, R. Wang, and K. Shen, "Effect of long-term laboratory aging on rheological properties and cracking resistance of polymer-modified asphalt binders at intermediate and low temperature range," Construction and Building Materials, vol. 226, pp. 767-777, 2019.

[30] B. W. Lou, Z. Z. Liu, A. M. Sha, M. Jia, and Y. P. Li, "Microwave absorption ability of steel slag and road performance of asphalt mixtures incorporating steel slag," Materials, vol. 13, no. 3, 2020.

[31] L. Qu, Y. Gao, H. Yao et al., "Preparation and performance analysis of high-viscosity and elastic recovery modified asphalt binder," Advances in Civil Engineering, vol. 2019, pp. 1-16, 2019.

[32] F. Zhang, J. Yu, and J. Han, "Effects of thermal oxidative ageing on dynamic viscosity, TG/DTG, DTA and FTIR of SBS- and SBS/sulfur-modified asphalts," Construction and Building Materials, vol. 25, no. 1, pp. 129-137, 2011.

[33] X. Xie, T. Hui, Y. Luo, H. Li, G. Li, and Z. Wang, "Research on the properties of low temperature and anti-UV of asphalt with nano- $\mathrm{ZnO} /$ nano- $\mathrm{TiO}_{2} /$ copolymer SBS composite modified in high-altitude areas," Advances in Materials Science and Engineering, vol. 2020, no. 5, pp. 1-15, 2020.

[34] J. Y. Yu, H. L. Zhang, P. Sun, and S. F. Zhao, "Laboratory performances of nano-particles/polymer modified asphalt mixtures developed for the region with hot summer and cold winter and field evaluation," Road Materials and Pavement Design, vol. 21, no. 6, 2020. 